\title{
The Spectroscopic and Conductive Properties of Ru(II) Complexes with Potential Anticancer Properties
}

\author{
Adebayo A. Adeniyi and Peter A. Ajibade \\ Department of Chemistry, University of Fort Hare, Private Bag X1314, Alice 5700, South Africa \\ Correspondence should be addressed to Peter A. Ajibade; pajibade@ufh.ac.za
}

Received 15 February 2014; Accepted 4 May 2014; Published 14 July 2014

Academic Editor: Stephen Cooke

Copyright (C) 2014 A. A. Adeniyi and P. A. Ajibade. This is an open access article distributed under the Creative Commons Attribution License, which permits unrestricted use, distribution, and reproduction in any medium, provided the original work is properly cited.

\begin{abstract}
Different density functional methods (DFT) have been used to optimize and study the chemistry of five potential anticancer complexes in terms of their electronic, conductive, and spectroscopic properties. Many of the computed properties in addition to the IR and QTAIM analysis of the NMR are dipole moment vector $\left(\mu_{i}\right)$, linear polarizability tensor $\left(\alpha_{i j}\right)$, first hyperpolarizability tensors $\left(\beta_{i j k}\right)$, polarizability exaltation index $(\Gamma)$, and chemical hardness $(\eta)$ of the complexes. Stable low energy geometries are obtained using basis set with effective core potential (ECP) approximation but, in the computation of atomic or molecular properties, the metal $\mathrm{Ru}$ atom is better treated with higher all electron basis set like DGDZVP. The spectroscopic features like the IR of the metal-ligand bonds and the isotropic NMR shielding tensor of the coordinated atoms are significantly influenced by the chemical environment of the participating atoms. The carboxylic and pyrazole units are found to significantly enhance the polarizabilities and hyperpolarizabilities of the complexes while the chloride only improves the polarity of the complexes. Fermi contacts (FC) have the highest effect followed by the PSO among all the four Ramsey terms which defined the total spin-spin coupling constant $\mathrm{J}(\mathrm{HZ})$ of these complexes.
\end{abstract}

\section{Introduction}

Ruthenium-based organometallic complexes are widely applied in medical research field as anticancer compounds [1-13]. Two of the ruthenium complexes, KP1019 [14, 15] and NAMI-A [16-19], have passed through the phase two medical tests as potential anticancer drugs and might rival cisplatin which has been the most effective and widely used anticancer agent [20-24]. Many other applications for ruthenium complexes in addition to study as anticancer agents are as photoluminescence, electrochemiluminescence, catalyst, and photochemical complexes [25-30]. The complexes used in this work are designed to play a dual role as anticancer and nonlinear optical (NLO) materials. Docking study of some of these complexes has been found to be promising than many of the RAPTA complexes [31]. The most widely screened ruthenium complexes as anticancer are the halfsandwich complexes [2,3,32-37]. RAPTA complexes as type of the half-sandwich ruthenium complexes under Dyson research teams have been experimentally proven as potential anticancer agents [22-24, 38-42]. The complexes (Figure 1) studied in this work have similar structures with another type of half-sandwich ruthenium anticancer complexes [43-52]. The main differences in these models of complexes compared to the type of complexes from the Sandler research team are the pyrazole and carboxylic units of interest that are incorporated into the bidentate or tridentate ligands coordinating to the metal through the nitrogen atoms.

Our interest in this work is to compute the chemical properties of these complexes in relation to the unique features of the carboxylic or pyrazole units, total stability, conductivity, and reactivity either as anticancer or NLO materials. Besides the limitation of the unknown targets of ruthenium anticancer complexes $[14,20,39,53-56]$ which is limiting their rational design and approval, other limitations in their application are the complexity of their reaction and instability [20]. In drug design there is need for a clear understanding of the physicochemical properties of the drug 


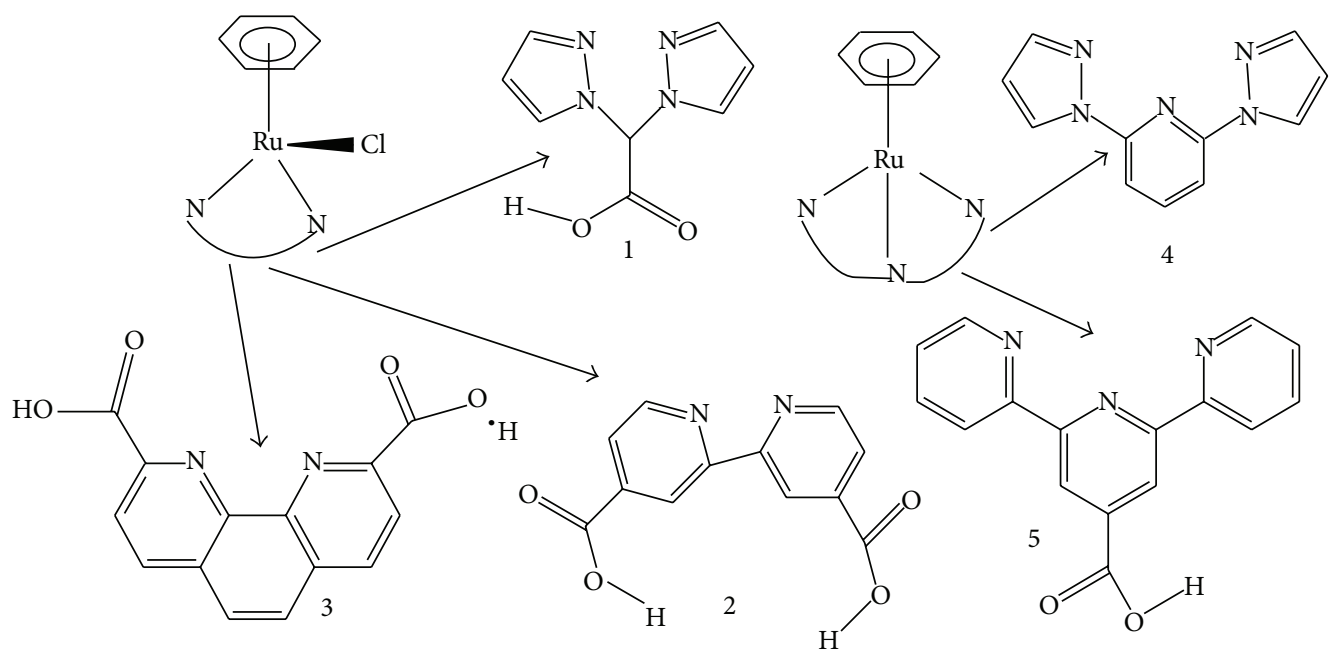

FIGURE 1: The schematic features showing all the bidentate ligands of complexes 1, 2, and 3 and tridentate ligands of complexes 4 and 5.

candidates [57] which will enhance their rational design. To understand the chemistry of these complexes, the IR spectroscopic differences, the isotropic NMR shielding $\left(\sigma_{\text {Iso }}\right)$, magnetizabilities $\left(\chi_{\text {Iso }}\right)$, the hardness $(\eta)$, hyperpolarizability $(\beta)$, polarizability exaltation index $(\Gamma)$ dipole $(\mu)$, and anisotropy polarizations $\left(\langle\alpha\rangle, \Delta \alpha_{1}, \Delta \alpha_{2}, \Delta \alpha_{3}\right)$ of these five complexes are computed. In addition to the spectroscopic features of these complexes, many factors computed in this work like the polarizabilities, hyperpolarizabilities [58], hardness $[59,60]$, and polarizability exaltation index [59], have been linked to the stability, reactivity, or selectivity [61] and conductivity of molecules. The main aim is to characterize and analyze the electric, conductive, and spectroscopic properties of the complexes in relation to the number and position of the carboxylic and pyrazole units. There is little known information about the hyperpolarizabilities of ruthenium metal complexes but many of the computed properties in this study have not been reported for these types of metal complexes to the best of our knowledge.

\section{Computational Method}

The geometries of the complexes were optimized twice using PBE0 hybrid density functional [62] and combined basis set SBKJC VDZ [63] with effective core potential (ECP) (for ruthenium and chloride atoms where applicable) while other atoms are treated with basis set $6-31 G^{*}$ in the first optimization that will be subsequently referred to as $\operatorname{ECP}(\mathrm{Ru}, \mathrm{Cl}) \mid 6-31 \mathrm{G}^{*}$ systems. In the second optimization, only the ruthenium atom is treated with SBKJC VDZ ECP basis set while other atoms are treated with improved basis set $6-31+G(d, p)$ and this will be referred to as $\operatorname{ECP}(R u) \mid 6-$ $31+\mathrm{G}(\mathrm{d}, \mathrm{p})$ systems. The PBE0 is obtained by casting the functional and correlation of Perdew, Burke, and Ernzerhof in a hybrid HF/DFT scheme with a fixed 1/4 ratio [64]. In application of SBKJC VDZ ECP basis set, 28 core electrons were removed from $\mathrm{Ru}(1 \mathrm{~s}, 2 \mathrm{~s}, 2 \mathrm{p}, 3 \mathrm{~s}, 3 \mathrm{p}$, and $3 \mathrm{~d})$ and 10 from $\mathrm{Cl}(1 \mathrm{~s}, 2 \mathrm{~s}$, and $2 \mathrm{p}$ ) atoms (where applicable) and were treated with pseudopotential while the valence electrons were treated with a double zeta quality functions. The choice of SBKJC VDZ ECP basis set is necessary for large systems of our type which also contain heavy metal like ruthenium. The choice combination of ECP basis set with PBE0 functional for the optimization is due to the past records of their effectiveness in computational study of metal clusters $[65,66]$ and because the ECP also incorporates relativistic corrections for the metal atoms [67]. This functional has been reported to improve the accuracy of excitation energies and charge transfer bands in metal complexes both in gas phase and in solution [68]. Also, the ECP basis set has been pointed out as a viable method for accurate calculations of transition metal polarizabilities [69]. All of the computed properties were done using Becke's three-parameter exchange [70] and LeeYang-Parr's correlation nonlocal functional which is usually denoted by B3LYP, combined with different combination of basis set. The properties of the systems optimized with $\mathrm{PBE} 0 / \mathrm{ECP}(\mathrm{Ru}) \mid 6-31+\mathrm{G}(\mathrm{d}, \mathrm{p})$ are computed with the combination of DGDZVP basis for ruthenium atom and 6$31+G(d, p)$ basis set for other atoms which will be further referred to as DGDZVP(Ru)|6-31+G(d,p). The properties of the same set of the optimized systems are also computed with the same combinations of basis set as was used for the optimization $(\mathrm{ECP}(\mathrm{Ru}) \mid 6-31+\mathrm{G}(\mathrm{d}, \mathrm{p}))$. The properties of all the systems optimized with lower basis sets $\operatorname{ECP}(\mathrm{Ru}, \mathrm{Cl}) \mid 6$ $31 \mathrm{G}^{*}$ were computed with the same combination of basis sets as used for their optimization $\left(\mathrm{ECP}(\mathrm{Ru}, \mathrm{Cl}) \mid 6-31 \mathrm{G}^{*}\right)$ and also computed with minimal all electron basis set $3-21 G$ [71] applied on all atoms. The external SBKJC VDZ ECP was obtained from EMSL Basis Set Library [72, 73] and incorporated into input files in a readable format for Gaussian 09 [74] suite of programs used for the computation. The NMR and one-bond NMR spin-spin coupling constants $J(A, B)[75$, 76] were computed in Gaussian package using the GIAO method. The wave function files (WFX) for the computation of QTAIM properties were obtained at the same level of theory through the fchk generated files using the AIMAll 
program package [77]. Intra- and interatomic properties were computed by the Proaim integration approach, as implemented in the AIMAll suite of programs. The accuracy of the integration process was guaranteed by keeping the atomic integral of the one-electron density Laplacian below the $10^{-4}$ a.u. within all atomic basins. In addition, the summation of all basin energies was compared with the total electronic energy of the molecule, calculated independently at the above-mentioned computational level, to check that the differences remain below the $1 \mathrm{kcal} / \mathrm{mol}$.

The correlation of the computed properties was done with $R$ statistical package [78] while the RMSD of the geometries obtained at different optimization levels was built with UCSF Chimera package [79].

\section{Results and Discussion}

3.1. The Geometry and the IR Spectroscopic. The geometry is optimized twice using the combined basis set $\mathrm{ECP}(\mathrm{Ru}, \mathrm{Cl}) \mid 6-$ $31 G^{*}$ for the first optimization and $\operatorname{ECP}(\mathrm{Ru}) \mid 6-31+\mathrm{G}(\mathrm{d}, \mathrm{p})$ for the second optimization. The zero imaginary obtained for the five complexes during the two methods of optimization is an indication that both methods detect the minimum geometry of the complexes except for complex 4 that was predicted during $\mathrm{ECP}(\mathrm{Ru}, \mathrm{Cl}) \mid 6-31 \mathrm{G}^{*}$ as transition with single imaginary frequency. There is no significant changes in the bond lengths $(\gg 0.01 \AA)$, angles $\left(\gg 2.0^{\circ}\right)$, and the conformations $(\gg 0.1)$ of the complexes when optimized with $\operatorname{ECP}(\mathrm{Ru}, \mathrm{Cl}) \mid 6-31 \mathrm{G}^{*}$ and with higher basis set $\operatorname{ECP}(\mathrm{Ru}) \mid 6-$ $31+G(d, p)$ (Table 1$)$. The little significant change observed is in the conformational change of the carboxylic units of complex 1 which is responsible for it having the highest recorded RMSD of 0.068 (Table 1) when the geometries from the two optimizations are matched.

The numbers of the vibrational modes observed for each of the complexes are 102,114,120,108, and 129 and are directly proportional to the number of atoms $36,40,42,38$, and 45 in each of the respective complexes 1,2, 3, 4, and 5. The IR spectra of the five complexes are shown in Figure 2 and the possible assignments of the vibration to the bonds stretching and bending are shown in Table 2. Differences in the complexes and their respective IR spectra were used to suggest the corresponding bond vibrations. The Ru-nitrogen $(\mathrm{Ru}-\mathrm{N})$ bonds are assigned to indicate the differences in the vibration of ruthenium bonding to pyrazole or pyridine or phenanthroline units. The peculiarity of weak vibrations around 700 for the complexes 1, 2, and 3 with chloride ligands which are not obvious in other complexes without chloride is an indication of $\mathrm{Ru}-\mathrm{Cl}$ vibration around this region. The $\mathrm{Ru}$-carbon $(\mathrm{Ru}-\mathrm{C})$ bonds are assigned to vibration at 797 which is common to all the complexes. The assigned $\mathrm{Ru}-\mathrm{C}$ vibrations are within the possible Metal-C vibrations (548829) reported for carbonyl metal bonds [83] and of that which was specifically reported for the $\mathrm{Ru}-\mathrm{C}$ vibration (838) [84]. The common vibrations around 1419 and that peculiar to complex 4 and at 1477 for other complexes are assigned to the possible $\mathrm{C}-\mathrm{C}$ and $\mathrm{C}-\mathrm{N}$ vibrations and can be equally suggested to be a result of $\mathrm{Ru}$-ligand $(\mathrm{Ru}-\mathrm{L})$ charge transfer
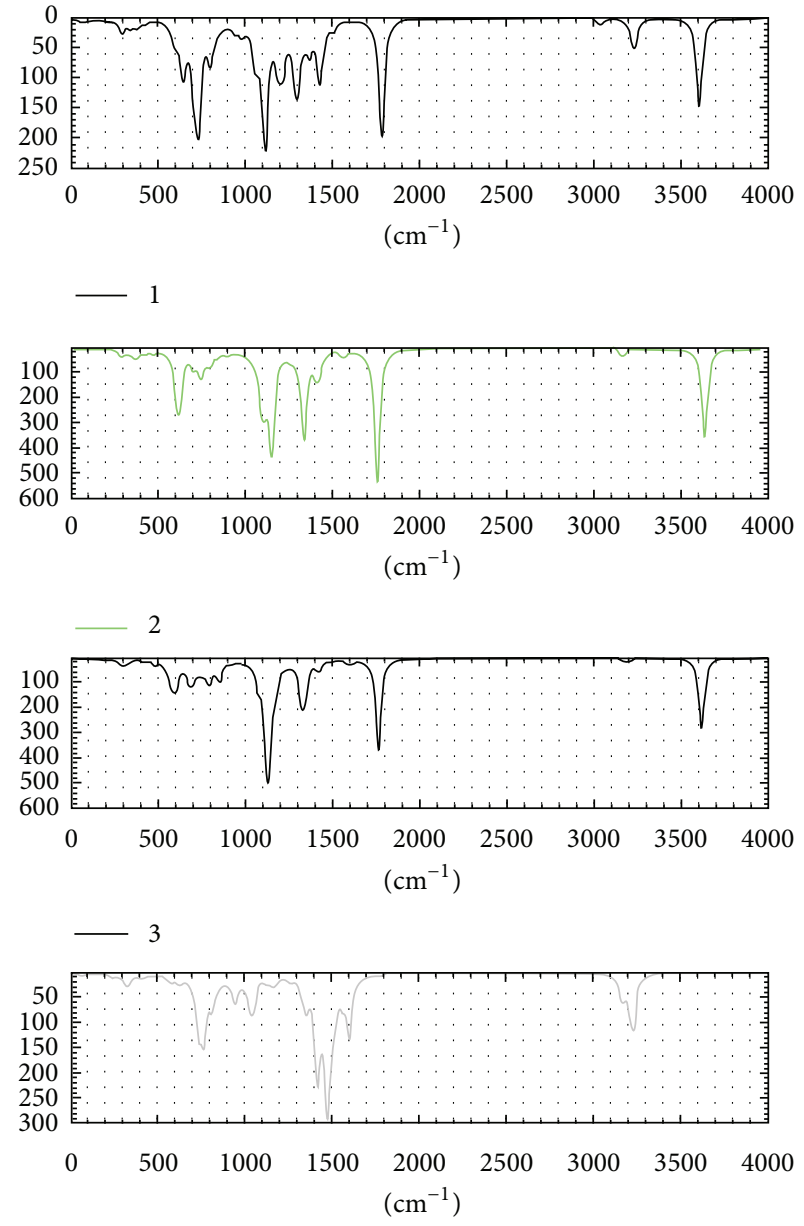

4

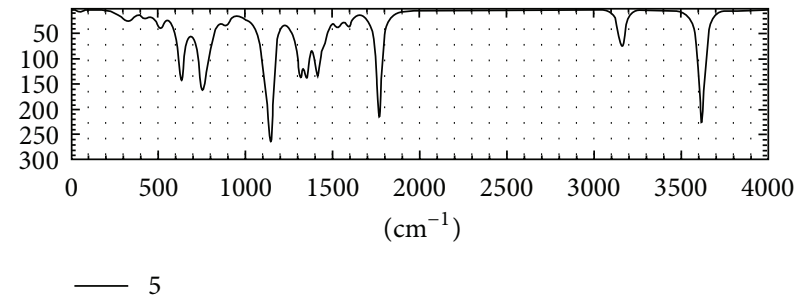

FIGURE 2: The IR spectra of the indicated complexes showed the variation in their vibrational modes.

[82]. All the vibrations at 3600-3625, 1758-1784, 1050-1150, and 735-745 are all peculiar to the complexes with carboxylic unit and are assigned to different modes of vibrations as indicated in Table 2.

\section{Spin-Spin Coupling $(\mathrm{J}(\mathrm{HZ}))$ of Ru-Ligand Bonds}

The four Ramsey terms, Fermi contact (FC), spin dipole (SD), diamagnetic spin orbit (DSO), and paramagnetic spin orbit (PSO), were used to determine the total nuclear 
TABLE 1: The selected bond lengths and angles of interest with the percentage of the alignment of each of the complexes optimized using different basis sets $\mathrm{ECP}(\mathrm{Ru}, \mathrm{Cl}) \mid 6-31 \mathrm{G}^{*}$ and $\mathrm{ECP}(\mathrm{Ru}) \mid 6-31+\mathrm{G}(\mathrm{d}, \mathrm{p})$.

\begin{tabular}{lcccccc}
\hline & & 1 & 2 & 3 & 4 & 5 \\
\hline \multirow{2}{*}{$\mathrm{Ru}-\mathrm{Cl}$} & $\mathrm{ECP}(\mathrm{Ru}, \mathrm{Cl}) \mid 6-31 \mathrm{G}^{*}$ & 2.444 & 2.444 & 2.390 & & \\
& $\mathrm{ECP}(\mathrm{Ru}) \mid 6-31+\mathrm{G}(\mathrm{d}, \mathrm{p})$ & 2.394 & 2.396 & 2.440 & & \\
\hline \multirow{2}{*}{$\mathrm{Ru}-\mathrm{N}$} & $\mathrm{ECP}(\mathrm{Ru}, \mathrm{Cl}) \mid 6-31 \mathrm{G}^{*}$ & $2.133,2.134$ & $2.10,2.10$ & $2.140,2.146$ & $2.166,2.166,{ }^{*} 2.089$ & $2.157,2.158,{ }^{*} 2.045$ \\
& $\mathrm{ECP}(\mathrm{Ru}) \mid 6-31+\mathrm{G}(\mathrm{d}, \mathrm{p})$ & $2.137,2.139$ & $2.096,2.096$ & $2.138,2.138$ & $2.162,2.162,{ }^{*} 2.084$ & $2.152,2.153,{ }^{*} 2.039$ \\
\hline \multirow{2}{*}{$\mathrm{Ru}-\mathrm{C}$ ranges } & $\mathrm{ECP}(\mathrm{Ru}, \mathrm{Cl}) \mid 6-31 \mathrm{G}^{*}$ & $2.225-2.234$ & $2.229-2.251$ & $2.233-2.252$ & $2.240-2.251$ & $2.251-2.268$ \\
& $\mathrm{ECP}(\mathrm{Ru}) \mid 6-31+\mathrm{G}(\mathrm{d}, \mathrm{p})$ & $2.222-2.232$ & $2.233-2.254$ & $2.236-2.253$ & $2.241-2.252$ & $2.252-2.269$ \\
\hline \multirow{2}{*}{$\mathrm{N}-\mathrm{Ru}-\mathrm{N}$} & $\mathrm{ECP}(\mathrm{Ru}, \mathrm{Cl}) \mid 6-31 \mathrm{G}^{*}$ & 83.045 & 76.995 & 77.375 & $107.984,{ }^{*} 72.054,{ }^{*} 72.051$ & $108.839,{ }^{*} 73.521,{ }^{*} 73.568$ \\
& $\mathrm{ECP}(\mathrm{Ru}) \mid 6-31+\mathrm{G}(\mathrm{d}, \mathrm{p})$ & 82.809 & 77.116 & 77.317 & $107.855,{ }^{*} 72.159,{ }^{*} 72.158$ & $108.654,{ }^{*} 73.632,{ }^{*} 73.672$ \\
\hline \multirow{2}{*}{$\mathrm{RMSD}$ of atoms in $\AA$} & & 0.068 & 0.004 & 0.017 & 0.011 & \\
\hline
\end{tabular}

The values for the complexes 4 and 5 with superscript “\#” indicated their association with the middle nitrogen of their tridentate.

TABLE 2: The assignment of the IR vibrations to different bonds in the complexes.

\begin{tabular}{|c|c|c|}
\hline Vibrations & Complex & Assignment \\
\hline $3600-3625$ & $1,2,3$, and 5 & O-H of carboxylic \\
\hline $1758-1784$ & $1,2,3$, and 5 & $\mathrm{C}=\mathrm{O}[80]$ of carboxylic \\
\hline $1050-1150$ & $1,2,3$, and 5 & O-C stretches (2-bands) \\
\hline $735-745$ & $1,2,4$, and 5 & $\mathrm{O}-\mathrm{H}$ bend (out-of-plane) \\
\hline 3228 & 1,4 & $\mathrm{C}-\mathrm{H}$ asymmetric vibration peculiar to pyrazol-1-ly unit \\
\hline $3050-3161$ & All & $\mathrm{C}-\mathrm{H}$ arene asymmetric vibration \\
\hline 1419 & All & $\begin{array}{l}\text { Charge transfer } \mathrm{Ru}-\mathrm{L}[81] \\
\mathrm{C}-\mathrm{C} \\
\text { Arene } v(\mathrm{C}-\mathrm{H}) \text { stretches }\end{array}$ \\
\hline 1337 & All but prominent in complex 2 & $\mathrm{C}-\mathrm{N}$ stretches \\
\hline 597 & $\begin{array}{l}\text { Complex } 3 \text { that is effect of carbonyl unit being very } \\
\text { close to metal }\end{array}$ & Charge transfer \\
\hline $614-642$ & Complexes $1,2,3$, and 5 & O-H bend (out-of-plane) of carboxylic unit \\
\hline 300 & Complexes $1,2,3$, and 5 & Peculiar to carboxylic \\
\hline 1477 & 4 & $\begin{array}{l}\mathrm{Ru}-\mathrm{L} \text { charge transfer }[82] \\
\mathrm{C}-\mathrm{C} ; \mathrm{C}-\mathrm{N}\end{array}$ \\
\hline 1419 & All & $\mathrm{Ru}-\mathrm{L}$ charge transfer $[82] ; \mathrm{C}-\mathrm{C} ; \mathrm{C}-\mathrm{N}$ \\
\hline 700 & $1,2,3$ & $\mathrm{Ru}-\mathrm{Cl}$ \\
\hline 751 & $2,4,5$ with pyridine has peculiar & $\mathrm{Ru}-\mathrm{N}(\mathrm{py})$ \\
\hline 847 & 3 & $\mathrm{Ru}-\mathrm{N}$ (phen) \\
\hline 731 & 1,4 & $\mathrm{Ru}-\mathrm{N}(\mathrm{pz})$ \\
\hline 765 & 4, 5 (strong) & $\begin{array}{l}\mathrm{Ru}-\mathrm{N}(\mathrm{py}) \text { should result from the strong long bond of } \\
\mathrm{Ru} \text { with mid pyridine unit }\end{array}$ \\
\hline 797 & All & $\mathrm{Ru}-\mathrm{C}$ \\
\hline 3161 & $2,4,5$ & $v(\mathrm{C}-\mathrm{H})$ antisymmetric stretches (py) \\
\hline 3224 & 1,4 & $v(\mathrm{C}-\mathrm{H})$ antisymmetric stretches $(\mathrm{pz})$ \\
\hline 505 & 5 & $\mathrm{Ru}-\mathrm{N}(\mathrm{py})$ close to $424-428$ assigned to $v(\mathrm{Ru}-\mathrm{S})[80]$ \\
\hline 300 & All & Bond deformations \\
\hline
\end{tabular}

spin-spin coupling (J) [85]. These Ramsey terms are computed with different combinations of basis sets. The properties computed with $\operatorname{DGDZVP}(\mathrm{Ru}) \mid 6-21+\mathrm{G}(\mathrm{d}, \mathrm{p})$ and 3$21 \mathrm{G}$ are shown in Supplementary Table S1, available online at http://dx.doi.org/10.1155/2014/656830, while those computed with $\operatorname{ECP}(\mathrm{Ru}) \mid 6-21+\mathrm{G}(\mathrm{d}, \mathrm{p})$ and $\operatorname{ECP}(\mathrm{Ru}, \mathrm{Cl}) \mid 6-21 \mathrm{G}^{*}$ are shown in Table S2. The FC and SD represent the spin polarization densities while DSO and PSO represent orbital current densities [85]. Also, the FC and SD describe the interaction of the electronic spin with the nuclear magnetic field which consists of two parts, namely, extended dipole field outside the nucleus and a strongly localized field inside the nucleus [86]. The SD term corresponds to the dipole field, whereas the FC term describes a contact interaction between 
TABLE 3: Correlation of computed Ramsey terms to the spin-spin coupling over all atoms in each of the complexes.

\begin{tabular}{lccccc}
\hline & 1 & 2 & 3 & 4 & 5 \\
& $J(\mathrm{HZ})$ & $J(\mathrm{HZ})$ & $J(\mathrm{HZ})$ & $J(\mathrm{HZ})$ & $J(\mathrm{HZ})$ \\
\hline FC & 0.71 & 0.68 & 0.71 & 0.99 & 0.99 \\
SD & 0.66 & 0.64 & 0.72 & 0.28 & 0.15 \\
PSO & 0.77 & 0.77 & 0.77 & 0.76 & 0.64 \\
DSO & 0.24 & 0.34 & 0.47 & 0.59 & 0.48 \\
$J(\mathrm{HZ})$ & 1.00 & 1.00 & 1.00 & 1.00 & 1.00 \\
\hline
\end{tabular}

electron spin and nuclear magnetic field at the surface of the nucleus (i.e., hyperfine interaction between nucleus and electron) [85]. Long-range coupling in p systems should contain substantial SD contributions if the coupling nuclei are incorporated into the p system [86].

The Ramsey terms computed with only minimal basis set 3-21G are in a close relationship with the one computed with higher basis set DGDZVP $(\mathrm{Ru}) \mid 6-21+\mathrm{G}(\mathrm{d}, \mathrm{p})$ but it underestimates the values of the FC and SD and consequentially the values of the total spin-spin coupling constant $(\mathrm{J}(\mathrm{HZ})$ ) (Table S1) while the magnitude of PSO and DMO remains virtually the same. However, the same trends of values obtained with $3-21 \mathrm{G}$ and DGDZVP $(\mathrm{Ru}) \mid 6-21+\mathrm{G}(\mathrm{d}, \mathrm{p})(R$-square $=0.9864 ; P$ value $=2.20 \mathrm{E}-016 ; F$-statistic $=3192)$ are a clear indication that the minimal basis set can equally reproduce a good feature of the Ramsey terms of these complexes. All the Ramsey properties computed with basis sets either when only the $\mathrm{Ru}$ atom is treated with $\mathrm{ECP}(\mathrm{ECP}(\mathrm{Ru}) \mid 6-21+\mathrm{G}(\mathrm{d}, \mathrm{p}))$ or when $\mathrm{Ru}$ and $\mathrm{Cl}$ atoms are treated with $\mathrm{ECP}(\mathrm{ECP}(\mathrm{Ru}, \mathrm{Cl}) \mid 6$ $21 \mathrm{G}^{*}$ ) significantly underestimate the Ramsey terms except the DSO which appears to be unaffected with core electron approximation with ECP (Table S2). The Ramsey term that was most underestimated when ECP was used is the FC term and there was no significant improvement even when the ECP was limited to Ru metal with application of higher basis set on all other atoms in the complexes $(\mathrm{ECP}(\mathrm{Ru}) \mid 6$ $21+G(d, p)$ ) (Table S2). This further supports the reported characteristics of the Ramsey term which pointed out that the $\mathrm{SD}$ coupling mechanism requires occupied and unoccupied non-s orbitals while FC operator probes the $s$-electrons at the sites of coupling nuclei $[86,87]$ which are predominantly the ECP approximated core orbitals. However, the trend and the values of the total spin-spin coupling constant $(\mathrm{J}(\mathrm{HZ}))$ of the $\mathrm{ECP}(\mathrm{Ru}) \mid 6-21+\mathrm{G}(\mathrm{d}, \mathrm{p})$ systems improved $(R$-square = $0.7781 ; P$ value $=7.28 \mathrm{E}-016 ; F$-statistic $=155.3)$ compared to the $\mathrm{ECP}(\mathrm{Ru}, \mathrm{Cl}) \mid 6-2 \mathrm{G}^{*}$ systems $(R$-square $=-0.007818$; $P$ value $=0.4215 ; F$-statistic $=0.6587)$.

The Ramsey terms which have the greatest magnitude are the FC term followed by the PSO while the DSO is the smallest. The least magnitude of DSO further supports the report that DSO is the least interesting and also the least investigated mechanism [86]. A large DSO contribution can only be expected if the charge distribution around one of the coupling nuclei strongly deviates from isotropy as can be found in certain transition metal atoms [85] which is not the case in these complexes.

The chloride atoms in complexes 1,2 , and 3 have the lowest magnitude of the FC and DSO but the highest SD and
PSO which consequentially lead to the highest magnitude of the J (HZ) compare to other coordinated atoms of the ligands. The coordinated nitrogen atoms have the highest magnitude of FC but lowest magnitude of PSO and DSO compared to other coordinated atoms in the complexes but their $\mathrm{J}(\mathrm{HZ})$ is lesser than that of the chloride atoms. The features of the PSO that show the chloride atoms as having the highest magnitude followed by the arene atoms and nitrogen atom being the least are an indication that the high electronegativity effect of chloride and a high $\pi$ strength of the arene strongly determine the magnitude of PSO. This is in agreement with the reports that show the possible relation of PSO coupling mechanism to bond order, $\pi$-strength, electronegativity, and the magnetizability of a bond $\left(\chi_{\text {Intrabond_Iso }}\right)$ [86]. The relatively same values of the spin-spin coupling of the chloride atoms in complexes 1 , 2 , and 3 are an indication that there is no serious effect on the coupling strength of the chloride to the ruthenium metal atom due to changes in their chemical environment (Table S1). The coupling spin-spin constant of the coordinated nitrogen atoms of the phenanthroline unit of complex 3 has the lowest spin-spin coupling constant among all the bidentate $\mathrm{Ru}-\mathrm{N}$ couplings. The coordinated nitrogen atom of the central pyridine unit of tridentate ligand of complex 4 has the lowest spin-spin coupling among all its coordinated nitrogen of the ligands while no significant variation is observed for the three coordinated nitrogen atoms of the terpyridine unit of complex 5. In all the atoms of the ligands that are coordinated to the Ru metal atom, the carbon atoms of the arene unit have the lowest magnitude of the total spin-spin coupling and a significant variation in the coupling strength of the carbon atoms of the same arene unit. There appear to be significant changes in the magnitude of the $\mathrm{SD}$ and consequential significant change in the coupling $\mathrm{J}(\mathrm{HZ})$ of the coordinated arene carbon atoms as the chemical environment changes from one complex to another.

In complexes 1,2, and 3 where there is chloride atom, a very high correlation of the SD with the PSO $(0.93,0.89$, and 0.98 , resp.) is observed but no such high correlation is observed for complexes $4(0.32)$ and $5(0.08)$ without the chloride atoms. The effect of SD on the total spin-spin coupling $(\mathrm{J}(\mathrm{HZ})$ ) was also high on the three complexes with chloride (Table 3) while the effect of the FC on the spin-spin coupling constant significantly improved in the complexes 4 and 5 without the chloride atoms. Generally, the Ramsey terms which have the highest effects on the total spin-spin coupling constants are FC and PSO while SD and DSO are average and depend on the type of the complexes (Table 3). 
Even though the magnitude of DSO is the least in all the complexes (Table S1), yet it has a significantly improved effect in complexes 4 and 5 (Table 3 ) that are without chloride ligand.

\section{NMR Properties of the Complexes}

The computed NMR properties using the combined basis set $\operatorname{DGDZVP}(\mathrm{Ru}) \mid 6-31+\mathrm{G}(\mathrm{d}, \mathrm{p})$ (Table S3) and a single minimal basis set $3-21 \mathrm{G}$ are in a closed range (Table $\mathrm{S} 4$ ) but when the $\mathrm{ECP}(\mathrm{Ru}) \mid 6-31+\mathrm{G}(\mathrm{d}, \mathrm{p})$ basis was used, the $\sigma_{\text {Iso }}$ of Ru atom was underestimated which equally affects the values obtained for other atoms (Table S5). There have been reported applications of ECP to study only the chemical shifts of the ligands and it was not expected to perform well for the shielding of the heavy atom since NMR parameters depend critically on the electron density in the nuclear regions which may not be accurately modelled by the RECPs approach [88]. It is also difficult to measure $\chi_{\text {Iso }}$ accurately, and the experimental value often includes large errors. The magnitudes of the $\chi_{\text {Iso }}, \sigma_{\text {Iso }}(A)$, and many other atomic properties computed with the minimal basis set 3-21G and $\operatorname{DGDZVP}(\mathrm{Ru}) \mid 6-$ $31+\mathrm{G}(\mathrm{d}, \mathrm{p})$ are relatively close. This observation further supports the view that the $\chi_{\text {Iso }}$ is generally insensitive to electron correlation corrections and vibrational corrections [89]. There are significant variations in the computed properties with ECP as the intra-atomic magnetizabilities $\left(\chi_{\text {Intra_Iso }}\right)$ of the ruthenium atom that was characterized with ECP basis set were underestimated while its $\chi_{\text {Intra_Iso }}$ or $\chi_{\text {bond_Iso }}$ was overestimated to compensate for the underestimated intra which consequentially lead to overestimation of the $\chi_{\text {Iso }}$ of ruthenium (compare Table S3 with Table S5). This observation does not completely agree with the reported view that relativistic effect in $\chi_{\text {Iso }}$ is much smaller, since the magnetizability does not require an accurate electronic structure in the vicinity of nuclei [89]. Magnetizability is expressed as a second derivative of the total electronic energy with respect to the external magnetic field [89]. The effect of ECP is much more prominent in the computed $\sigma_{\text {Iso }}(A)$ as there was no compensation for the underestimated intraatomic isotropic shielding $\left(\sigma_{\text {Iso }}(A, A)\right)$ which consequentially lead to the complete underestimation of the $\sigma_{\text {Iso }}(A)$ of the ruthenium atom.

The hydrogen atoms that are involved in $\mathrm{HB}$ are characterized with higher $\chi_{\text {bond_Iso }}$, lower $\chi_{\text {Intra_Iso }}$, and lower $\sigma_{\text {Iso }}(A)$ than any other hydrogen atoms in the complex (Figure 3 ). The QTAIM properties obtained from the highest combination of basis set DGDZVP(6-31+G(d,p)) (Table S3) will be considered for further discussion. The magnitude of $\chi_{\text {bond_Iso }}$ of $\mathrm{Ru}$ atom is higher than other atoms in the complexes but it is not the case for its total bonding isotropic NMR shielding $\left(\sigma_{\text {Iso }}\left(A^{\prime}, A\right)\right)$ contribution. The highest among each of the $\chi_{\text {bond_Iso }}$ of Ru to all the coordinated atoms is the arene carbon atoms ( $\mathrm{Ru}-\mathrm{C}$ bonding) except in complex 3 where the highest contribution is towards the $\mathrm{Ru}-\mathrm{Cl}$ bonding. The amount of $\chi_{\text {bond_Iso }}$ contribution of $\mathrm{Ru}$ atom to any coordinated atom is in proportion to the amount contributed by the coordinating atoms and is also higher except for the $\mathrm{Ru}-\mathrm{Cl}$ bonding where it is lower. This type of proportion does not occur in the case of the $\sigma_{\text {Iso }}\left(A^{\prime}, A\right)$ of $\mathrm{Ru}$ atom to the coordinated atoms. It is $\mathrm{Ru}$ atom $\operatorname{Sigma}$ Isso $(A, B)$ contribution that is far either higher as in the case of $\mathrm{Ru}-\mathrm{C}$ bonding with arene atoms or lower as in the case of $\mathrm{Ru}-\mathrm{N}$ or $\mathrm{Ru}-\mathrm{Cl}$ atoms bonding. The nature of each Sigma_Iso $(A, B)$ shows that the arene unit is electron deficient $\pi$-ligand while the $\mathrm{Ru}, \mathrm{Cl}$, and $\mathrm{N}$ unit are electron rich. It has been shown that in ionic and polar systems current density flow is localized in atomic basins and the contribution of the $\chi_{\text {Intra_Iso }}$ to the total $\chi_{\text {Iso }}$ of the atom is minimal which is reverse in covalently bonded molecules where the contribution of $\chi_{\text {bond_Iso }}$ to the $\chi_{\text {Iso }}$ is considerable and in some cases, like aromatic molecules, even surpasses the $\chi_{\text {Intra_Iso }}$ [90]. Therefore, the lowest values obtained for the $\mathrm{Cl}$ atom $\chi_{\text {Intra_Iso }}($ Table S3) is an indication that it could be ionic bond. It has been demonstrated that $\chi_{\text {Intra_Iso }}$ is able to verify the exact nature of aromaticity/antiaromaticity among different molecules and also distinguish the correct aromaticity order among the sets of aromatic/antiaromatic molecules [90].

The selected correlation of the computed QTAIM NMR atomic properties with the $\chi_{\text {Iso }}$ and NMR $\sigma_{\text {Iso }}(A)$ are shown in Table 4 . Besides those shown in Table 4 , the values of anisotropy is highly correlation with $\chi_{\text {Intra_Iso }}$ with the correlation values of $0.69,0.62,0.68,0.96$, and 0.89 for the respective complexes while it is inverse correlation with $\chi_{\text {Intra_Iso }}$ with correlation values of $-0.80,-0.79,-0.83,-0.86$, and -0.80 for the respective complexes. It is interesting to point out that there is a very strong correlation of atomic charges with the $\chi_{\text {Intra_Iso }}$ as was previously observed in the literature [90] but with the $\chi_{\text {bond_Iso }}$ it is low (Table 4$)$. Also, the correlation of the atomic charges with the $\sigma_{\text {Iso }}(A, A)$ is very low. The $\sigma_{\text {Iso }}(A)$ of the atom is found to be highly correlated with the electronic kinetic energy of an atom $(K(A))$, the approximation to virialbased total energy of an atom $\left(K_{-}\right.$Scaled $\left.(A)\right)$, and the number of electrons localized in an atom $(\mathrm{LI}(A))$ but relatively lower correlated with the number of electron delocalization from an atom $\left(\mathrm{DI}\left(A, A^{\prime}\right)\right)$ and the total dipole moment contribution of an atom $(\mu(A))$.

The high correlation obtained from the computed atomic properties makes us propose a model for easy computation of NMR properties of molecules.

The proposed model equation is

$$
\begin{aligned}
\operatorname{SigmaIso}(A)= & C_{0}+C_{1} * \operatorname{ABS}\left(X_{1}\right) \\
& +C_{2} * X_{2}+C_{3}\left(X_{3}^{2}\right)+C_{4} * X_{4}+C_{5} * X_{5},
\end{aligned}
$$

where $X_{1}=q(A), X_{2}=K(A), X_{3}=K$ Scaled $(A), X_{4}=$ $\mathrm{LI}(A)$, and $X_{5}=\mathrm{DI}\left(A, A^{\prime}\right) / 2$.

The $C_{i}$ values, the level of the correlation, and the significance of the QTAIM properties $\left(X_{i}\right)$ used to model the $\sigma_{\text {Iso }}(A)$ are shown in Table 5 . From the values of the $R^{2}$, there is a clear indication that there is a very high correlation of the $\sigma_{\text {Iso }}(A)$ with the computed electronic kinetic energy of atoms $(K(A)), \operatorname{LI}(A)$, approximation to virial-based total energy of atoms $\left(K \_\right.$Scaled $\left.(A)\right)$, and $\operatorname{DI}\left(A, A^{\prime}\right)$. However, despite the high correlation, wide residual ranges are observed for 


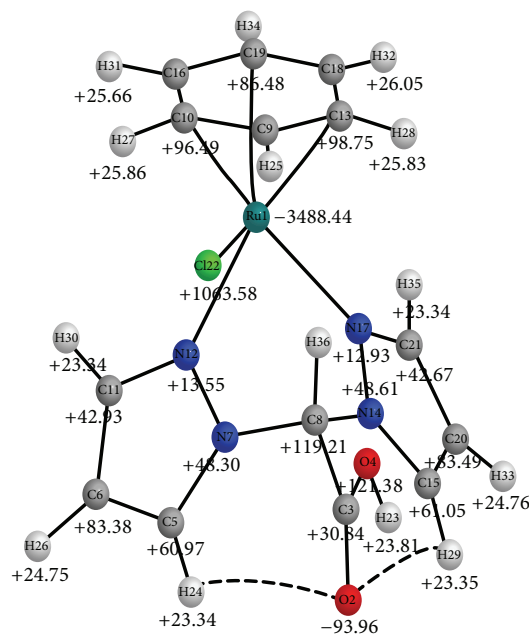

(a)

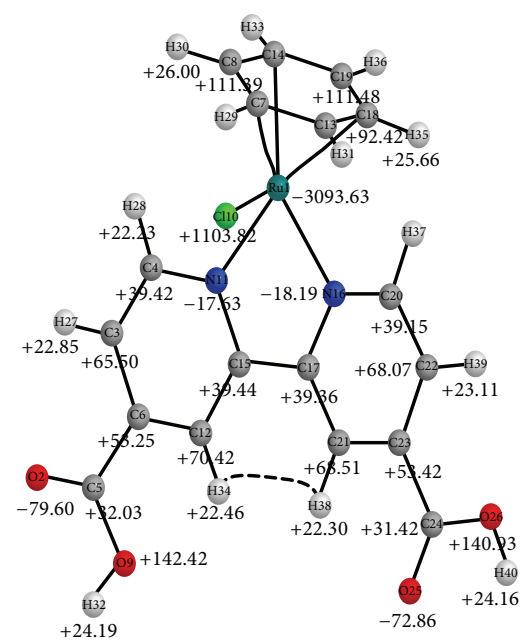

(b)

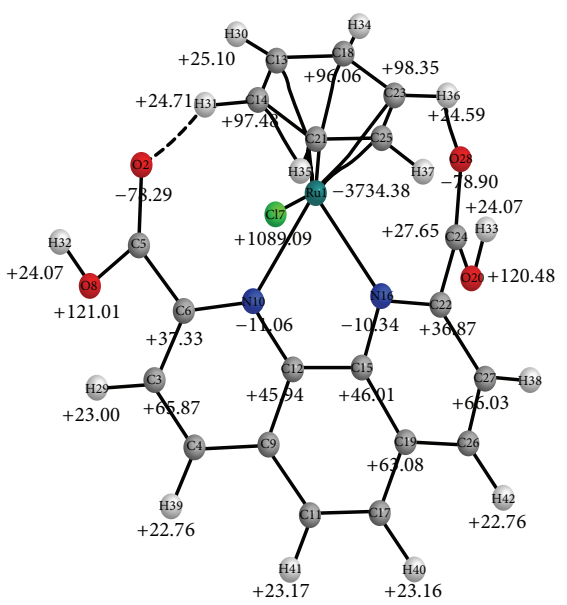

(c)

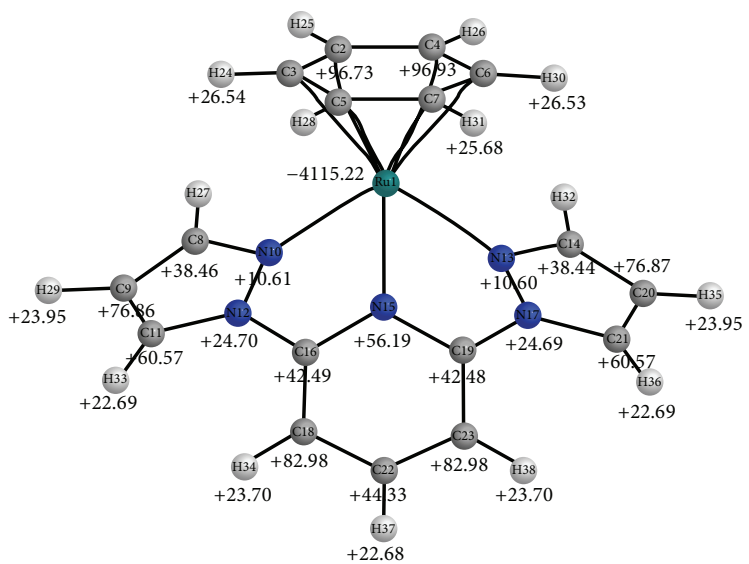

(d)

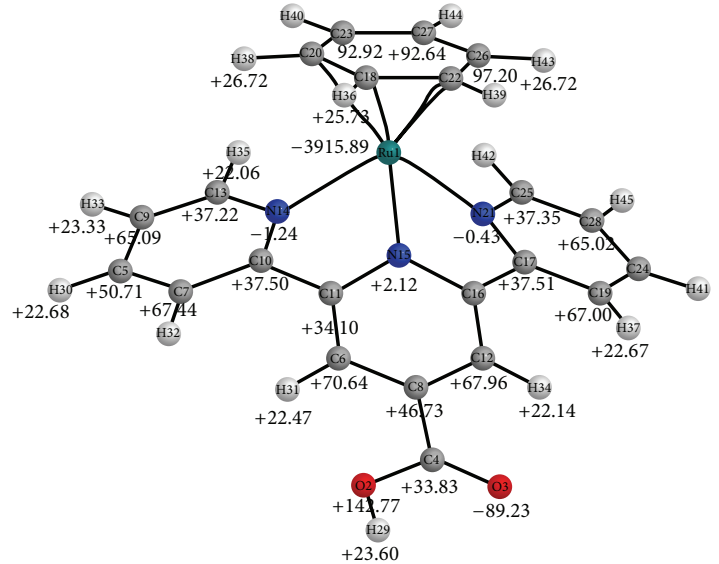

(e)

FIgURE 3: The optimized geometries of the complexes showing the isotropic NMR shielding of selected atoms computed with $\operatorname{DGDZVP}(\mathrm{Ru}) \mid 6-31+\mathrm{G}(\mathrm{d}, \mathrm{p})$.

TABLE 4: The correlation of the computed atomic NMR properties of the complexes.

\begin{tabular}{|c|c|c|c|c|c|c|c|c|c|c|}
\hline & \multicolumn{2}{|c|}{ Complex 1} & \multicolumn{2}{|c|}{ Complex 2} & \multicolumn{2}{|c|}{ Complex 3} & \multicolumn{2}{|c|}{ Complex 4} & \multicolumn{2}{|c|}{ Complex 5} \\
\hline & $\sigma_{\text {Iso }}(A)$ & $\chi_{\mathrm{Iso}}(A)$ & $\sigma_{\text {Iso }}(A)$ & $\chi_{\mathrm{Iso}}(A)$ & $\sigma_{\text {Iso }}(A)$ & $\chi_{\mathrm{Iso}}(A)$ & $\sigma_{\text {Iso }}(A)$ & $\chi_{\text {Iso }}(A)$ & $\sigma_{\text {Iso }}(A)$ & $\chi_{\mathrm{Iso}}(A)$ \\
\hline$q(A)$ & -0.30 & 0.53 & -0.25 & 0.52 & -0.25 & 0.54 & -0.33 & 0.56 & -0.25 & 0.58 \\
\hline $\operatorname{Vol}(A), 0.001$ & 0.07 & -0.83 & 0.10 & -0.84 & 0.07 & -0.85 & -0.39 & -0.68 & -0.28 & -0.64 \\
\hline$K(A)$ & -0.93 & 0.10 & -0.91 & 0.01 & -0.93 & 0.08 & -1.00 & 0.24 & -1.00 & 0.26 \\
\hline$K \_$Scaled $(A)$ & 0.93 & -0.10 & 0.91 & -0.01 & 0.93 & -0.08 & 1.00 & -0.24 & 1.00 & -0.26 \\
\hline $\mathrm{LI}(A)$ & -0.75 & -0.27 & -0.72 & -0.36 & -0.75 & -0.30 & -0.94 & -0.04 & -0.92 & -0.05 \\
\hline $\mathrm{DI}\left(A, A^{\prime}\right) / 2$ & -0.28 & -0.40 & -0.27 & -0.38 & -0.25 & -0.40 & -0.21 & -0.78 & -0.20 & -0.67 \\
\hline$\chi_{\text {Intra_Iso }}(A)$ & -0.89 & 0.68 & -0.86 & 0.66 & -0.88 & 0.65 & -0.98 & 0.45 & -0.94 & 0.50 \\
\hline$\chi_{\text {Ibond_Iso }}(A)$ & 0.71 & 0.30 & 0.68 & 0.35 & 0.75 & 0.25 & 0.81 & 0.31 & 0.73 & 0.37 \\
\hline$\chi_{\text {Iso }}(A)$ & -0.37 & 1.00 & -0.33 & 1.00 & -0.35 & 1.00 & -0.29 & 1.00 & -0.31 & 1.00 \\
\hline$|\mu(A)|$ & -0.29 & -0.42 & -0.25 & -0.48 & -0.14 & -0.57 & -0.33 & -0.44 & -0.28 & -0.26 \\
\hline$\sigma_{\text {Iso }}(A, A)$ & 1.00 & -0.37 & 1.00 & -0.32 & 1.00 & -0.34 & 1.00 & -0.28 & 1.00 & -0.30 \\
\hline$\sigma_{\mathrm{Iso}}\left(A^{\prime}, A\right)$ & -0.31 & -0.31 & -0.30 & -0.28 & -0.28 & -0.26 & -0.25 & -0.71 & -0.25 & -0.57 \\
\hline$\sigma_{\text {Iso }}(A)$ & 1.00 & -0.37 & 1.00 & -0.33 & 1.00 & -0.35 & 1.00 & -0.29 & 1.00 & -0.31 \\
\hline Anisotropy & -0.93 & 0.08 & -0.92 & -0.01 & -0.93 & 0.04 & -1.00 & 0.21 & -0.99 & 0.17 \\
\hline
\end{tabular}


TABLE 5: The fitted properties of the factors used in the proposed isotropic shielding model.

\begin{tabular}{|c|c|c|c|c|c|}
\hline & 1 & 2 & 3 & 4 & 5 \\
\hline (Intercept) & $2.98 E+001$ & $3.95 E+001$ & $3.89 E+001$ & $-1.01 E+002$ & 35.19 \\
\hline $\operatorname{abs}(q(A))$ & $-5.40 E+001$ & $-5.43 E+001$ & $-5.37 E+001$ & $4.22 E+001$ & $-5.32 E+001$ \\
\hline$K(A)$ & $4.04 E+000$ & $3.92 E+000$ & $3.97 E+000$ & $-1.35 E+001$ & 3.34 \\
\hline$\left(K \_ \text {Scaled }(A)\right)^{2}$ & $-1.01 E-003$ & $-9.74 E-004$ & $-1.01 E-003$ & $2.64 E-003$ & $-8.96 E-004$ \\
\hline $\mathrm{LI}(A)$ & $-3.52 E+001$ & $-2.97 E+001$ & $-3.15 E+001$ & $7.71 E+001$ & $-2.43 E+001$ \\
\hline $\mathrm{DI}\left(A, A^{\prime}\right) / 2$ & $2.42 E+001$ & $3.81 E+000$ & $5.61 E+000$ & $1.89 E+002$ & $3.96 E+000$ \\
\hline$R$-squared & 0.9968 & 0.9941 & 0.9966 & 0.9998 & 0.9974 \\
\hline$P$ value & $2.20 E-016$ & $2.20 E-016$ & $2.20 E-016$ & $2.20 E-016$ & $2.20 E-016$ \\
\hline Min residue & -92.515 & -104.098 & -93.863 & -37.232 & -113.183 \\
\hline Max residue & 117.752 & 114.178 & 100.135 & 12.616 & 117.111 \\
\hline
\end{tabular}

the complexes 1,2, 3, and 5 with carboxylic unit. The carboxylic group is responsible for a wide margin as the oxygen and the hydroxyl units are the most poorly fitted among all the atoms in each of the complexes.

\section{Polarizability and Hyperpolarizabilities of the Complexes}

The energy $(E)$ of a molecule that is subjected to a static electric field $(F)$ can be expressed as

$$
\begin{aligned}
E= & E^{0}-\mu_{i} F_{i}-\frac{1}{2} \alpha_{i j} F_{i} F_{j}-\frac{1}{6} \beta_{i j k} F_{i} F_{j} F_{k} \\
& -\frac{1}{26} \gamma_{i j k l} F_{i} F_{j} F_{k} F_{l}-\cdots,
\end{aligned}
$$

where $E^{0}$ is the energy of the molecule in the absence of an electronic field, $\mu_{i}$ is the component of the dipole moment vector, $\alpha_{i j}$ is the linear polarizability tensor, $\beta_{i j k}$ and $\gamma_{i j k l}$ are first and second hyperpolarizability tensors, where $i, j$, and $k$ label are the $x, y$, and $z$ components, respectively [68].

The terms in the energy of molecule due to the effect of the external electric fields are computed except the second hyperpolarizability tensor $\left(\gamma_{i j k l}\right)$.

The dipole was computed by

$$
\mu=\left(\mu_{x}^{2}+\mu_{y}^{2}+\mu_{z}^{2}\right)^{1 / 2}
$$

The anisotropy polarization was calculated using

$$
\begin{gathered}
\langle\alpha\rangle=\frac{1}{3}\left(\alpha_{x x}+\alpha_{y y}+\alpha_{z z}\right) \\
\Delta \alpha_{1}=\frac{1}{2}\left(\alpha_{x x}+\alpha_{y y}\right)-\alpha_{z z} \\
\Delta \alpha_{2}=\left\{\frac { 1 } { 2 } \left[\left(\alpha_{x x}-\alpha_{y y}\right)^{2}+\left(\alpha_{x x}-\alpha_{z z}\right)^{2}-\left(\alpha_{y y}-\alpha_{z z}\right)^{2}\right.\right. \\
\left.\left.+6\left(\alpha_{x y}^{2}+\alpha_{x z}^{2}+\alpha_{y z}^{2}\right)\right]\right\}^{1 / 2} \\
\Delta \alpha_{3}=\left[\left(\Delta \alpha_{2}\right)^{2}-\left(\Delta \alpha_{1}\right)^{2}\right]^{1 / 2}
\end{gathered}
$$

Besides the mean polarizability $(\langle\alpha\rangle)$ and polarizability anisotropies $(\alpha 1, \alpha 2$, and $\alpha 3)$, we also evaluated the polarizability exaltation index $(\Gamma)$, which is determined as $\Gamma=$ $\alpha(\mathrm{mol})-\Sigma i\langle\alpha\rangle i$, where $\alpha(\mathrm{mol})$ is the mean polarizability of a molecule and $\Sigma_{i}\langle\alpha\rangle_{i}$ is the summation of the atomic polarizability of the atoms which constitute the molecule. According to literature [59], calculated $\Gamma$ values have been employed to estimate relative aromaticity of furan homologues and stabilities of atomic clusters. A large negative $\Gamma$ value denotes a very stable structure.

The accurate single values of first static hyperpolarizability $(\beta)$ of the complexes were computed using quasiPythagorean problem [58] on the 10 components of the $3 \times$ $3 \times 3$ matrix as $\beta_{x x x}, \beta_{x x y}, \beta_{x y y}, \beta_{y y y}, \beta_{x x z}, \beta_{x y z}, \beta_{y y z}, \beta_{x z z}$, $\beta_{y z z}$, and $\beta_{z z z}$, respectively, from G03 output as

$$
\beta_{\mathrm{tot}}=\left(\beta_{x}^{2}+\beta_{y}^{2}+\beta_{z}^{2}\right)^{1 / 2}
$$

where $\beta_{x}=\left(\beta_{x x x}+\beta_{x y y}+\beta_{x z z}\right), \beta_{y}=\left(\beta_{y y y}+\beta_{y x x}+\beta_{y z z}\right)$, and $\beta_{z}=\left(\beta_{z x x}+\beta_{z y y}+\beta_{z z z}\right)$.

Since the values of $\beta$ in G09 are reported in atomic units (a.u.), the calculated $\beta$ total values were converted into electrostatic units (esu) ( 1 a.u. $\left.=8.6393 \times 10^{-33} \mathrm{esu}\right)$.

Hardness $(\eta)$ is a molecular property commonly employed to characterize the relative stability and reactivity of series of compounds. An operative expression of $\eta$ is given in terms of ionization energy (IE) and electron affinity (EA), which can be approximated by the highest occupied molecular orbital (HOMO) and the lowest unoccupied molecular orbital (LUMO) energies $(\varepsilon)$, respectively,

$$
\eta=\frac{1}{2}(\mathrm{IE}-\mathrm{EA}) \approx \frac{1}{2}\left(\varepsilon_{\mathrm{HOMO}}-\varepsilon_{\mathrm{LUMO}}\right) .
$$

The calculated $\eta$ values are included in Table 6 with all other conductive properties of the complexes. In agreement with the relative energies, the most stable isomer is predicted to be the hardest one [59]. However, the molecules having a small energy gap known as soft and having a large energy gap are known as hard molecules [60]. The hardness has been found to be a good indicator of more stable molecular isomers $[91,92]$. It is also pointed out to be a measure of the degree of electron localization, molecular polarizability, and resonance energy [93]. Pearson observed that a large HOMO-LUMO 
TABLE 6: The conductive properties of the complexes.

\begin{tabular}{|c|c|c|c|c|c|c|c|c|c|}
\hline & Dipole & $\langle\alpha\rangle$ & $\Delta \alpha_{1}$ & $\Delta \alpha_{2}$ & $\Delta \alpha_{3}$ & $\Gamma$ & $\beta$ in esu $(1 \times 10-30)$ & Gap in $\mathrm{KJ} / \mathrm{Mol}$ & $\eta \mathrm{KJ} / \mathrm{Mol}$ \\
\hline \multicolumn{10}{|c|}{$\mathrm{ECP} \mid 6-31 \mathrm{G}^{*}$} \\
\hline Bpyrazace & 3.36 & 216.91 & 21.47 & 23.65 & 49.34 & $4.52 E+00$ & 5.19 & 156.35 & 78.17 \\
\hline Dpynic & 6.60 & 279.95 & 178.26 & 178.69 & 75.21 & $1.35 E-02$ & 21.58 & 173.10 & 86.55 \\
\hline Phth & 7.71 & 293.04 & -57.11 & 147.14 & 9193.44 & $1.06 E-02$ & 14.22 & 159.95 & 79.97 \\
\hline Razol & 2.78 & 239.30 & 120.99 & 132.10 & 1405.16 & $6.07 E-03$ & 4.43 & 221.67 & 110.84 \\
\hline Terpy & 5.41 & 304.08 & 176.09 & 179.75 & 651.20 & $1.69 E-02$ & 4.66 & 210.70 & 105.35 \\
\hline \multicolumn{10}{|c|}{$3-21 G$} \\
\hline Bpyrazace & 6.78 & 191.82 & 30.93 & 42.17 & 410.65 & -20.57 & 4.13 & 395.11 & 197.56 \\
\hline Dpynic & 6.60 & 248.11 & 157.78 & 157.85 & 12.16 & -31.83 & 11.98 & 314.14 & 157.07 \\
\hline Phth & 8.43 & 262.55 & -55.83 & 134.05 & 7426.85 & -30.48 & 7.26 & 294.69 & 147.34 \\
\hline Razol & 3.15 & 218.38 & 112.59 & 126.98 & 1723.92 & -20.91 & 3.08 & 391.80 & 195.90 \\
\hline Terpy & 4.96 & 274.65 & 165.37 & 170.87 & 923.74 & -29.41 & 2.81 & 366.20 & 183.10 \\
\hline \multicolumn{10}{|c|}{ DGDZVP|6-31+G(d,p) } \\
\hline Bpyrazace & 6.85 & 224.50 & -26.12 & 41.27 & 510.43 & -8.50 & 3.60 & 405.87 & 202.93 \\
\hline Dpynic & 6.85 & 290.46 & 157.90 & 158.15 & 39.09 & -17.15 & 12.96 & 307.11 & 153.55 \\
\hline Phth & 8.28 & 303.87 & 124.09 & 125.04 & 118.04 & -16.09 & 6.66 & 301.63 & 150.82 \\
\hline Razol & 2.47 & 246.42 & 106.75 & 117.33 & 1184.90 & -9.55 & 2.75 & 390.01 & 195.00 \\
\hline Terpy & 6.07 & 311.90 & 156.81 & 160.52 & 588.77 & -14.47 & 3.12 & 358.54 & 179.27 \\
\hline \multicolumn{10}{|c|}{$\mathrm{ECP} \mid 6-31+\mathrm{G}(\mathrm{d}, \mathrm{p})$} \\
\hline Bpyrazace & 5.80 & 233.00 & -29.28 & 48.32 & 738.82 & $-1.89 E-03$ & & 238.15 & 119.08 \\
\hline Dpynic & 5.89 & 307.61 & 179.09 & 179.83 & 133.67 & $6.16 E-04$ & & 165.29 & 82.64 \\
\hline Phth & 6.95 & 319.96 & 138.24 & 138.69 & 62.08 & $-7.98 E-04$ & & 162.12 & 81.06 \\
\hline Razol & 1.83 & 255.97 & 115.41 & 124.10 & 1040.71 & $-2.24 E-04$ & & 221.85 & 110.92 \\
\hline Terpy & 4.65 & 326.37 & 168.22 & 170.74 & 427.26 & $2.45 E-03$ & & 218.62 & 109.31 \\
\hline
\end{tabular}

gap increases stability which suggests that molecules seem to follow a rule of nature to arrange them so as to be as hard as possible [94].

In both cases of ECP basis sets $\operatorname{ECP}(\mathrm{Ru}, \mathrm{Cl}) \mid 6-31 \mathrm{G}^{*}$ and ECP $(\mathrm{Ru}) \mid 6-31+\mathrm{G}(\mathrm{d}, \mathrm{p})$, the computed conductive properties are overestimated beside the dipole $(\mu)$, polarizability exaltation index $(\Gamma)$, band gap, and hardness $(\eta)$ that were underestimated. However, $\operatorname{ECP}(\mathrm{Ru}) \mid 6-31+\mathrm{G}(\mathrm{d}, \mathrm{p})$ give better results that follow the same trend with the basis set $\operatorname{DGDZVP}(\mathrm{Ru}) \mid 6-31+\mathrm{G}(\mathrm{d}, \mathrm{p})$. The trend of the results obtained from $3-21 G$ is very similar to the best result obtained from DGDZVP $(\mathrm{Ru}) \mid 6-31+\mathrm{G}(\mathrm{d}, \mathrm{p})$ basis sets but there is little overestimation of the values of $\Gamma$ and underestimation of other properties. The computed hyperpolarizability values of these complexes are found to be lower than that observed for RAPTA complexes [95] but the NLO properties of complex 2 are higher than some of the reported high hyperpolarizability materials of ruthenium complexes with redoxswitching noninnocent ligands (NILs) [68] and many of the h5-monocyclopentadienylnitrilecobalt complexes [96]. This implies that these complexes will have intense intramolecular CT between metal and ligand (MLCT or LMCT) which is responsible for their relatively large value of $\beta$ as a result of $\pi$ back-donation in the complexes $[96,97]$. Complex 2 has the highest value of the first hyperpolarizabilities $(\beta)$ while complex 5 has the least. The trend of the magnitude of computed conductivity properties of the complexes for dipole, $\langle\alpha\rangle, \Delta \alpha_{1}, \Delta \alpha_{2}, \Delta \alpha_{3}, \Gamma, \beta$, and band gap (or $\eta$ ) are
$3<1=2<5<4 ; 5<3<2<4<1 ; 2<5<3<4<1 ; 5<2$ $<3<4<1 ; 4 \ll 5<1<3<2 ; 2<3<5<4<1 ; 2 \ll 3<1<4$ $<5$; and $1<4<5<2<3$, respectively. The computed value of $\Delta \alpha_{3}$ using different basis sets does not follow the same trend which is an indication that the values of $\Delta \alpha_{3}$ are very sensitive to the type of the basis sets. The polarizabilities properties of complexes 2 and 5 are relatively high except for the $\Delta \alpha_{3}$ which is an indication that the pyridine as bidentate and tridentate in the respective complexes contributes to the polarizabilities. The complex 4 has the lowest dipole moment because there is no carboxylic unit which would have improved its polarity which is responsible also for its poor polarizabilities, first static hyperpolarizabilities $(\beta)$, and higher band gap. Since the values of $\Gamma$ can be used to predict the stability of the complexes [59], therefore, complexes 2 and 3 may probably be the most stable and coupling with their lowest band gap (very soft) will make them very reactive [98] which may eventually help in their anticancer activities. Also, complexes 2 and 3 have the highest values of $\beta$ which is an indication that they are the best NLO materials which may eventually help in their anticancer activities.

\section{Conclusions}

The electronic, conductive, and spectroscopic properties of five ruthenium-based complexes are computed using density functional theory (DFT). The properties computed are 
related to the unique features of their carboxylic or pyrazole units, the total stability, conductivity, and reactivity of these complexes as either anticancer or NLO materials. Both applications of the ECP basis sets $\mathrm{ECP}(\mathrm{Ru}, \mathrm{Cl}) \mid 6-31 \mathrm{G}^{*}$ and $\operatorname{ECP}(\mathrm{Ru}) \mid 6-31+\mathrm{G}(\mathrm{d}, \mathrm{p})$ with the hybrid DFT functional PBE0 locate the minimum geometries of the complexes except the complex 4 that was predicted as transition when optimized with $\operatorname{ECP}(\mathrm{Ru}, \mathrm{Cl}) \mid 6-31 \mathrm{G}^{*}$ basis sets. There are no significant changes in the geometries when comparing the geometries from the two optimization methods. Though application of the ECP basis sets give optimized stable geometries of the complexes but computing the properties like the $\sigma_{\text {Iso }}(A)$, polarizabilities, and hyperpolarizabilities with ECP gives either overestimated or underestimated values. The properties computed with the minimal basis set $3-21 \mathrm{G}$ are very similar to the one computed with the combination of higher basis set DGDZVP $(\mathrm{Ru}) \mid 6-31+\mathrm{G}(\mathrm{d}, \mathrm{p})$ which is an indication that minimum basis set can be an advantage in the computation of the large molecules of these types. The difference in the IR features of these complexes shows that there is either bathochromic or hypsochromic shift in the IR vibration modes of the metal-ligand bonds like $\mathrm{Ru}-\mathrm{N}$ as a result of the change in the chemical environment of participating atoms.

The Ramsey term which has the greatest magnitude and effect on the computed spin-spin coupling constant $\mathrm{J}(\mathrm{HZ})$ is the FC term followed by the PSO and SD while the DSO is least. The J (HZ) properties of the $\mathrm{Ru}-\mathrm{Cl}$ are the highest among all the present Ru-Ligand bonds and do not significantly change due to change in the chemical environment of the complexes. Next to it is the $\mathrm{Ru}-\mathrm{N}$, but the magnitude of its $\mathrm{J}(\mathrm{HZ})$ changes with the change in the chemical environment as the $\mathrm{Ru}-\mathrm{N}$ of complex 3 with phenanthroline environment is characterized with the lowest magnitude among all the computed J (HZ) of $\mathrm{Ru}-\mathrm{N}$ in the complexes.

The hydrogen atoms that are involve in hydrogen bonding (HB) are characterized with higher $\chi_{\text {bond_Iso }}$ and $\chi_{\text {Intra_Iso }}$ and lower $\sigma_{\text {Iso }}(A)$ than any other hydrogen atom in the complexes. The isotropic bonding contribution of $\mathrm{Ru}$ atom to the coordinated atoms ( $\chi_{\text {bond_so }}$ ) is far higher as in the case of $\mathrm{Ru}-\mathrm{C}$ bonding with arene atoms or lower as in the case of $\mathrm{Ru}-\mathrm{N}$ or $\mathrm{Ru}-\mathrm{Cl}$ atoms bonding. The nature of each $\chi_{\text {bond_Iso }}$ shows that the arene unit is electron deficient $\pi$-ligand while the $\mathrm{Ru}, \mathrm{Cl}$, and $\mathrm{N}$ units are electron rich. Also the lowest values obtained for the $\mathrm{Cl}$ atom $\chi_{\text {bond_Iso }}$ are an indication that it could be ionic bond. The values of anisotropy show high correlation with $\chi_{\text {Intra_Iso }}$ but inverse correlation with $\chi_{\text {bond_sso }}$. The $\sigma_{\text {Iso }}(A)$ is found to be highly correlated with the electronic kinetic energy of an atom $(K(A))$, the approximation to virial-based total energy of an atom $\left(K \_\right.$Scaled $\left.(A)\right)$, and the number of electrons localized in an atom $(\operatorname{Loc}(A))$.

Other computed properties show that complexes 2 and 3 with two units of carboxylic are better NLO materials characterized with lower band gap and higher hyperpolarizabilities. Also, complexes 2 and 3 are predicted as the most stable and characterized with the highest value of $\Gamma$ and the most reactive with lowest band gap (very soft). Also, the pyrazole units appear to contribute to the NLO features of complexes 1 and 4 which are found to be better NLO materials than complex 5 despite the absence of carboxylic unit in complex 4. The presence of the chloride ligand in complexes 1,2 , and 3 does not have any effect on the conductive properties computed except that it enhances the polarity of the complexes resulting in their higher dipole above complexes 4 and 5 without the chloride ligand.

\section{Conflict of Interests}

The authors declare that there is no conflict of interests regarding the publication of this paper.

\section{Acknowledgments}

The authors gratefully acknowledged the financial support of Govan Mbeki Research and Development Centre, University of Fort Hare, South Africa. The CHPC in South Africa is gratefully acknowledged for providing the computing facilities and some of the software programs that are used for the computation.

\section{References}

[1] J. Ruiz, C. Vicente, C. de Hero, and D. Bautista, "A novel ruthenium(II) arene based intercalator with potent anticancer activity," Dalton Transactions, vol. 26, pp. 5071-5073, 2009.

[2] A. Martinez, J. Suarez, T. Sand, R. S. Magliozzi, and R. A. Sanchez-Delgado, "Interactions of arene- $\mathrm{Ru}(\mathrm{II})$-chloroquine complexes of known antimalarial and antitumor activity with human serum albumin (HSA) and transferring," Journal of Inorganic Biochemistry, vol. 105, no. 1, pp. 39-45, 2011.

[3] C. Gossans, I. Tavernelli, and U. Rothlisberger, "DNA structural distortions induced by ruthenium-arene anticancer compounds," Journal of the American Chemical Society, vol. 130, pp. 10921-10928, 2008.

[4] N. Gligorijević, S. Aranđelović, L. Filipović et al., "Picolinate ruthenium(II)-arene complex with in vitro antiproliferative and antimetastatic properties: Comparison to a series of ruthenium(II)-arene complexes with similar structure," Journal of Inorganic Biochemistry, vol. 108, pp. 53-61, 2012.

[5] E. Alessio, G. Mestroni, A. Bergamo, and G. Sava, "Ruthenium antimetastatic agents," Current Topics in Medicinal Chemistry, vol. 4, no. 15, pp. 1525-1535, 2004.

[6] A. Bergamo, C. Gaiddon, J. H. Schellens, J. H. Beijnen, and G. Sava, "Approaching tumour therapy beyond platinum drugs: status of the art and perspectives of ruthenium drug candidates," Journal of Inorganic Biochemistry, vol. 106, pp. 90-99, 2012.

[7] I. Bratsos, D. Urankar, E. Zangrando et al., "1-(2-Picolyl)substituted 1,2,3-triazole as novel chelating ligand for the preparation of ruthenium complexes with potential anticancer activity," Dalton Transactions, vol. 40, pp. 5188-5199, 2011.

[8] M. Brindell, E. Kuliś, S. K. Elmroth, K. Urbańska, and G. Stochel, "Light-induced anticancer activity of $\left[\mathrm{RuCl}_{2}(\mathrm{DMSO})_{4}\right]$ complexes," Journal of Medicinal Chemistry, vol. 48, no. 23, pp. 7298-7304, 2005.

[9] V. Rajendiran, M. Murali, E. Suresh, M. Palaniandavar, V. S. Periasamy, and M. A. Akbarsha, "Non-covalent DNA binding 
and cytotoxicity of certain mixed-ligand ruthenium(II) complexes of 2,2' -dipyridylamine and diimines," Dalton Transactions, no. 16, pp. 2157-2170, 2008.

[10] A. Romerosa, T. Campos-Malpartida, C. Lidrissi et al., "Synthesis, characterization, and DNA binding of new watersoluble cyclopentadienyl ruthenium(II) complexes incorporating phosphines," Inorganic Chemistry, vol. 45, no. 3, pp. 12891298, 2006.

[11] W. F. Schmid, R. O. John, G. Mühlgassner et al., "Metalbased paullones as putative CDK inhibitors for antitumor chemotherapy," Journal of Medicinal Chemistry, vol. 50, no. 25, pp. 6343-6355, 2007.

[12] S. K. Singh, S. Joshi, A. R. Singh, J. K. Saxena, and D. S. Pandey, "DNA binding and topoisomerase II inhibitory activity of water-soluble ruthenium(II) and rhodium(III) complexes," Inorganic Chemistry, vol. 46, pp. 10869-10876, 2007.

[13] C. Tan, J. Liu, L. Chen, S. Shi, L. Ji, and J. Inorg, "Synthesis, structural characteristics, DNA binding properties and cytotoxicity studies of a series of $\mathrm{Ru}(\mathrm{III})$ complexes," Journal of Inorganic Biochemistry, vol. 102, no. 8, pp. 1644-1653, 2008.

[14] P. Heffeter, K. Bock, B. Atil et al., "Intracellular protein binding patterns of the anticancer ruthenium drugs $\mathrm{KP}_{1019}$ and $\mathrm{KP}_{1339}$," Journal of Biological Inorganic Chemistry, vol. 15, pp. 737-748, 2010.

[15] G. Zhao and H. Lin, "Metal complexes with aromatic Ncontaining ligands as potential agents in cancer treatment," Current Medicinal Chemistry-Anti-Cancer Agents, vol. 5, pp. 137-147, 2005.

[16] M. Bacac, A. C. Hotze, K. van der et al., "The hydrolysis of the anti-cancer ruthenium complex NAMI-A affects its DNA binding and antimetastatic activity: an NMR evaluation.," Journal of Inorganic Biochemistry, vol. 98, pp. 402-412, 2004.

[17] A. H. Velders, A. Bergamo, E. Alessio et al., "Synthesis and chemical-pharmacological characterization of the antimetastatic NAMI-A-type $\mathrm{Ru}(\mathrm{III})$ complexes (Hdmtp)[trans$\left.\mathrm{RuCl}_{4}(\mathrm{dmso}-\mathrm{S})(\mathrm{dmtp})\right], \quad(\mathrm{Na})\left[\right.$ trans $\left.-\mathrm{RuCl}_{4}(\mathrm{dmso}-\mathrm{S})(\mathrm{dmtp})\right]$, and $\left[m e r-\mathrm{RuCl}_{3}\left(\mathrm{H}_{2} \mathrm{O}\right)(\mathrm{dmso}-\mathrm{S})(\mathrm{dmtp})\right](\mathrm{dmtp}=$ 5,7-Dimethyl[1,2,4]triazolo[1,5-a]pyrimidine)," Journal of Medicinal Chemistry, vol. 47, no. 5, pp. 1110-1121, 2004.

[18] A. V. Vargiu, A. Robertazzi, A. Magistrato, P. Ruggerone, and P. Carloni, "The hydrolysis mechanism of the anticancer ruthenium drugs NAMI-A and ICR investigated by DFT-PCM calculations," The Journal of Physical Chemistry B, vol. 112, pp. 4401-4409, 2008.

[19] P. Mura, M. Camalli, L. Messori, F. Piccioli, P. Zanello, and M. Corsini, "Synthesis, structural characterization, solution chemistry, and preliminary biological studies of the ruthenium(III) complexes $[\mathrm{TzH}]\left[\right.$ trans $\left.-\mathrm{RuCl}_{4}(\mathrm{Tz})_{2}\right]$ and $[\mathrm{TzH}]\left[\right.$ trans $-\mathrm{RuCl}_{4}$ (DMSO)(Tz)].(DMSO), the thiazole analogues of antitumor ICR and NAMI-A," Inorganic Chemistry, vol. 43, pp. 3863-3670, 2004.

[20] C. S. Allardyce, A. Dorcier, C. Scolaro, and P. J. Dyson, "Development of organometallic (organo-transition metal) pharmaceuticals," Applied Organometallic Chemistry, vol. 19, no. 1, pp. $1-10,2005$.

[21] P. J. Dyson and G. Sava, "Metal-based antitumour drugs in the post genomic era," Dalton Transactions, vol. 23, no. 16, pp. 19291933, 2006.

[22] S. Chatterjee, S. Kundu, A. Bhattacharyya, C. G. Hartinger, and P. J. Dyson, "The ruthenium(II)-arene compound RAPTA-C induces apoptosis in EAC cells through mitochondrial and p53JNK pathways," Journal of Biological Inorganic Chemistry, vol. 13, pp. 1149-1155, 2008.

[23] M. Groessl, Y. O. Tsybin, C. G. Hartinger, B. K. Keppler, and P. J. Dyson, "Ruthenium versus platinum: interactions of anticancer metallodrugs with duplex oligonucleotides characterised by electrospray ionisation mass spectrometry," Journal of Biological Inorganic Chemistry, vol. 15, no. 5, pp. 677-688, 2009.

[24] A. E. Egger, C. G. Hartinger, A. K. Renfrew, and P. J. Dyson, "Metabolization of $\left[\mathrm{Ru}\left(\eta^{6}-\mathrm{C}_{6} \mathrm{H}_{5} \mathrm{CF}_{3}\right)(\mathrm{pta}) \mathrm{Cl}_{2}\right]$ : a cytotoxic RAPTA-type complex with a strongly electron withdrawing arene ligand," Journal of Biological Inorganic Chemistry, vol. 15, pp. 919-927, 2010.

[25] P. Byabartta, S. K. Jasimuddin, G. Mostafa, T.-H. Lu, and C. Sinha, "The synthesis, spectral studies and electrochemistry of 1,10-(phenanthroline)-bis-1-alkyl-2-(arylazo)imidazoleruthenium(II) perchlorate. Single crystal X-ray structure of $\left[\mathrm{Ru}(\right.$ phen $\left.)(\text { HaaiMe })_{2}\right]\left(\mathrm{ClO}_{4}\right)_{2}$ [phen=1,10-phenanthroline, HaaiMe=1-methyl-2-(phenylazo)imidazole]," Polyhedron, vol. 22, pp. 849-859, 2003.

[26] H. A. J. Al-Lawati, F. E. O. Suliman, S. M. Z. Al Kindy, A. M. Al-Lawati, G. B. Varma, and I. E. M. Nour, "Enhancement of on chip chemiluminescence signal intensity of tris $(1,10-$ phenanthroline)-ruthenium(II) peroxydisulphate system for analysis of chlorpheniramine maleate in pharmaceutical formulations," Talanta, vol. 82, pp. 1999-2002, 2010.

[27] X. M. Chen, G. H. Wu, J. M. Chen et al., "A novel electrochemiluminescence sensor based on bis(2,2 '-bipyridine)-5-amino1,10-phenanthroline ruthenium(II) covalently combined with graphite oxide," Biosensors and Bioelectronics, vol. 26, no. 2, pp. 872-876, 2010.

[28] H. Wei, J. Yin, and E. Wang, "Bis(2,2'-bipyridine)(5,6-epoxy5,6-dihydro-[1,10] phenanthroline)ruthenium: synthesis and electrochemical and electrochemiluminescence characterization," Analytical Chemistry, vol. 80, pp. 5635-5639, 2008.

[29] E. Rajalakshmanan and V. Alexander, "Synthesis, luminescence, and electrochemical studies of tris (homoleptic) ruthenium (II) and osmium (II) complexes of $6^{\prime}$-tolyl-2, 2': $4^{\prime}, 2^{\prime \prime}$-terpyridine," Inorganic Chemistry, vol. 46, pp. 6252-6260, 2007.

[30] H. J. Bolink, L. Cappelli, E. Coronado, and P. Gaviña, "Observation of electroluminescence at room temperature from a ruthenium(II) bis-terpyridine complex and its use for preparing light-emitting electrochemical cells," Inorganic Chemistry, vol. 44, no. 17, pp. 5966-5968, 2005.

[31] A. A. Adeniyi and P. A. Ajibade, "Inhibitory activities and possible anticancer targets of $\mathrm{Ru}(\mathrm{II})$-based complexes using computational docking method," Journal of Molecular Graphics and Modelling, vol. 38, pp. 60-69, 2012.

[32] S. Grgurić-Sipka, I. Ivanović, G. Rakić et al., "Ruthenium(II)arene complexes with functionalized pyridines: synthesis, characterization and cytotoxic activity," European Journal of Medicinal Chemistry, vol. 45, pp. 1051-1058, 2010.

[33] B. Biersack, M. Zoldakova, K. Effenberger, and R. Schobert, "Synthesis of $[1,2,4]$ triazolo[1,5-a]pyridines of potential PGE2 inhibitory properties," European Journal of Medicinal Chemistry, vol. 44, no. 5, pp. 1972-1975, 2010.

[34] F. Linares, M. A. Galindo, S. Galli, M. A. Romero, J. A. Navarro, and E. Barea, "Tetranuclear coordination assemblies based on half-sandwich ruthenium(II) complexes: noncovalent binding to DNA and cytotoxicity," Inorganic Chemistry, vol. 48, no. 15, pp. 7413-7420, 2009. 
[35] S. Das, S. Sinha, R. Britto, K. Somasundaram, and A. G. Samuelson, "Cytotoxicity of half sandwich ruthenium(II) complexes with strong hydrogen bond acceptor ligands and their mechanism of action," Journal of Inorganic Biochemistry, vol. 104, pp. 93-104, 2010.

[36] T. Gianferrara, I. Bratsos, E. Iengo et al., "Synthetic strategies towards ruthenium-porphyrin conjugates for anticancer activity," Dalton Transactions, vol. 38, pp. 10742-10756, 2009.

[37] E. Meggers, G. E. Atilla-Gokcumen, K. Gründler, C. Frias, and A. Prokop, "Inert ruthenium half-sandwich complexes with anticancer activity," Dalton Transactions, no. 48, pp. 1088210888, 2009.

[38] A. Casini, C. Gabbiani, F. Sorrentino et al., "Emerging protein targets for anticancer metallodrugs: inhibition of thioredoxin reductase and cathepsin B by antitumor ruthenium (II)-arene compounds," Journal of Medicinal Chemistry, vol. 51, no. 21, pp. 6773-6781, 2008.

[39] W. H. Ang, E. Daldini, C. Scolaro, R. Scopelliti, L. JuilleratJeannerat, and P. J. Dyson, "Development of organometallic ruthenium-arene anticancer drugs that resist hydrolysis," Inorganic Chemistry, vol. 45, pp. 9006-9013, 2006.

[40] C. A. Vock, W. H. Ang, C. Scolaro et al., "Development of ruthenium antitumor drugs that overcome multidrug resistance mechanisms," Journal of Medicinal Chemistry, vol. 50, no. 9, pp. 2166-2175, 2007.

[41] W. H. Ang, E. Daldini, L. Juillerat-Jeanneret, and P. J. Dyson, "Strategy to tether organometallic ruthenium-arene anticancer compounds to recombinant human serum albumin," Inorganic Chemistry, vol. 46, no. 22, pp. 9048-9050, 2007.

[42] W. H. Ang, A. de Luca, C. Chapuis-Bernasconi, L. JuilleratJeanneret, M. Lo Bello, and P. J. Dyson, "Organometallic ruthenium inhibitors of glutathione-S-transferase P1-1 as anticancer drugs," ChemMedChem, vol. 2, no. 12, pp. 1799-1806, 2007.

[43] F. Barragán, P. López-Senín, and L. Salassa, "Photocontrolled DNA binding of a receptor-targeted organometallic ruthenium(II) complex," Journal of the American Chemical Society, vol. 133, pp. 14098-14108, 2011.

[44] T. Bugarcic, A. Habtemariam, J. Stepankova et al., "The contrasting chemistry and cancer cell cytotoxicity of bipyridine and bipyridinediol ruthenium(II) arene complexes," Inorganic Chemistry, vol. 47, no. 24, pp. 11470-11486, 2008.

[45] M. Castellano-Castillo, H. Kostrhunova, V. Marini et al., "Binding of mismatch repair protein MutS to mispaired DNA adducts of intercalating ruthenium(II) arene complexes," Journal of Biological Inorganic Chemistry, vol. 13, no. 6, pp. 993-999, 2008.

[46] S. J. Dougan, A. Habtemariam, S. E. McHale, S. Parsons, and P. J. Sadler, "Catalytic organometallic anticancer complexes," Proceedings of the National Academy of Sciences of the United States of America, vol. 105, pp. 11628-11633, 2008.

[47] S. J. Dougan, M. Melchart, A. Habtemariam, S. Parsons, and P. J. Sadler, "A Neutral spirocyclic hexacoordinated germanium(IV) complex: hypervalent germanium compounds with sulfurcontaining eight-membered rings," Inorganic Chemistry, vol. 45, pp. 10882-10894, 2006.

[48] R. Fernández, M. Melchart, A. Habtemariam, S. Parsons, and P. J. Sadler, "Use of chelating ligands to tune the reactive site of half-sandwich ruthenium(II)-arene anticancer complexes," Chemistry, vol. 10, no. 20, pp. 5173-5179, 2004.

[49] Y. Fu, A. Habtemariam, A. M. Basri, D. Braddick, G. J. Clarkson, and P. J. Sadler, "Structure-activity relationships for organometallic osmium arene phenylazopyridine complexes with potent anticancer activity," Dalton Transactions, no. 40, pp. 10553-10562, 2011

[50] A. Habtemariam, M. Melchart, R. Fernandez et al., "Structureactivity relationships for cytotoxic ruthenium(II) arene complexes containing $\mathrm{N}, \mathrm{N}-$, N,O-, and $\mathrm{O}, \mathrm{O}$-chelating ligands," Journal of Medicinal Chemistry, vol. 49, no. 23, pp. 6858-6868, 2006.

[51] H. Kostrhunova, J. Florian, O. Novakova et al., "DNA interactions of monofunctional organometallic osmium(II) antitumor complexes in cell-free media," Journal of Medicinal Chemistry , vol. 51, pp. 3635-3643, 2008.

[52] H. K. Liu, F. Wang, J. A. Parkinson, J. Bella, and P. J. Sadler, "Ruthenation of duplex and single-stranded d(CGGCCG) by organometallic anticancer complexes," Chemistry, vol. 12, pp. 6151-6165, 2006.

[53] G. Sava, A. Bergamoa, and P. J. Dyson, "Metal-based antitumour drugs in the post-genomic era: what comes next?" Dalton Transactions, vol. 40, no. 36, pp. 9069-9075, 2011.

[54] G. Gasser, I. Ott, and N. Metzler-Nolte, "Organometallic anticancer compounds," Journal of Medicinal Chemistry, vol. 54, no. 1, pp. 3-25, 2011.

[55] S. Page, "Education in chemistry," 2012, http://www.rsc.org/eic/.

[56] C. S. Allardyce and P. J. Dyson, "Ruthenium in medicine: current clinical uses and future prospects," Platinum Metals Review, vol. 45, no. 2, pp. 62-69, 2001.

[57] J. Pratuangdejkul, P. Jaudon, and O. C. Ducrocq, "Cation- $\pi$ interactions in serotonin: conformational, electronic distribution, and energy decomposition analysis ," Journal of Chemical Theory and Computation, vol. 2, pp. 746-760, 2006.

[58] P. S. Liyanage, R. M. de Silva, and K. M. N. de Silva, "Nonlinear optical (NLO) properties of novel organometallic complexes: high accuracy density functional theory (DFT) calculations," Journal of Molecular Structure, vol. 639, pp. 195-201, 2003.

[59] A. Alparone, "Dipole (hyper)polarizabilities of fluorinated benzenes: an ab initio investigation," Journal of Fluorine Chemistry, vol. 144, pp. 94-101, 2012.

[60] M. Karabacak and M. Cinar, "FT-IR, FT-Raman, UV spectra and DFT calculations on monomeric and dimeric structure of 2-amino-5-bromobenzoic acid," Spectrochimica Acta A: Molecular and Biomolecular Spectroscopy, vol. 86, pp. 590-599, 2012.

[61] E. E. Ebenso, T. Arslan, F. Kandemirli, N. Caner, and I. Love, "Quantum chemical studies of some rhodanine azosulpha drugs as corrosion inhibitors for mild steel in acidic medium," International Journal of Quantum Chemistry, vol. 110, no. 5, pp. 1003-1018, 2010.

[62] C. Adamo and V. Barone, "Toward reliable density functional methods without adjustable parameters: the PBE0 model," The Journal of Chemical Physics, vol. 110, no. 13, pp. 6158-6170, 1999.

[63] W. J. Stevens, M. Krauss, H. Basch, and P. G. Jasien, "Relativistic compact effective potentials and efficient, shared-exponent basis sets for the third-, fourth-, and fifth-row atoms," Canadian Journal of Chemistry, vol. 70, pp. 612-630, 1992.

[64] J. P. Perdew, K. Burke, and M. Ernzerhof, "Generalized gradient approximation made simple," Physical Review Letters, vol. 77, pp. 3865-3868, 1996.

[65] B. Marchal, P. Carbonniére, D. Begue, C. Pouchan, and P. Carbonniére, "Structural and vibrational determination of small gallium-arsenide clusters from $\operatorname{CCSD}(\mathrm{T})$ and DFT calculations," Chemical Physics Letters, vol. 453, no. 1-3, pp. 49-54, 2008 . 
[66] R. Marchal, P. Carbonnière, and C. Pouchan, "Structural and vibrational properties prediction of $\mathrm{Sn}_{n} \mathrm{Te}_{n}$ clusters $(n=2-$ 8) using the GSAM approach," Computational and Theoretical Chemistry, vol. 990, pp. 100-105, 2012.

[67] A. Bagno and M. Bonchio, "DFT calculations of ${ }^{99} \mathrm{Ru}$ chemical shifts with all-electron and effective core potential basis sets," European Journal of Inorganic Chemistry, vol. 2002, no. 6, pp. 1475-1483, 2002.

[68] Y. Liu, C.-G. Liu, S.-L. Sun, G.-C. Yang, and Y.-Q. Qiu, "Redox-switching second-order nonlinear optical responses of $\mathrm{N}^{\wedge} \mathrm{N}^{\wedge} \mathrm{N}$ ruthenium complexes," Computational and Theoretical Chemistry, vol. 979, pp. 112-118, 2012.

[69] N. P. Labello, A. M. Ferreira, and H. A. Kurtz, "Utilizing relativistic effective core potentials for accurate calculations of molecular polarizabilities on transition metal compounds," The Journal of Physical Chemistry A, vol. 110, pp. 13507-13513, 2006.

[70] A. D. Becke, "Density-functional thermochemistry. III. The role of exact exchange," The Journal of Chemical Physics, vol. 98, pp. 5648-5652, 1993.

[71] K. D. Dobbs and W. J. Hehre, "Molecular orbital theory of the properties of inorganic and organometallic compounds 5 . Extended basis sets for first-row transition metals," Journal of Computational Chemistry, vol. 6, pp. 861-879, 1987.

[72] D. J. Feller, "The role of databases in support of computational chemistry calculations," Journal of Computational Chemistry, vol. 17, pp. 1571-1586, 1996.

[73] K. L. Schuchardt, B. T. Didier, T. Elsethagen et al., "Basis set exchange: a community database for computational sciences," Journal of Chemical Information and Modeling, vol. 47, no. 3, pp. 1045-1052, 2007.

[74] M. J. Frisch, G. W. Trucks, H. B. Schlegel et al., Gaussian 09, Gaussian, Inc., Wallingford, Conn, USA, 2009.

[75] T. Helgaker, M. Watson, and N. C. Handy, "Analytical calculation of nuclear magnetic resonance indirect spin-spin coupling constants at the generalized gradient approximation and hybrid levels of density-functional theory," Journal of Chemical Physics, vol. 113, pp. 9402-9409, 2000.

[76] V. Sychrovsky, J. Grafenstein, and D. Cremer, "Nuclear magnetic resonance spin-spin coupling constants from coupled perturbed density functional theory," The Journal of Chemical Physics, vol. 113, no. 9, pp. 3530-3547, 2000.

[77] T. A. Keith, "AIMAll (Version 12.06.03)," TK Gristmill Software, Overland Park, Kan, USA, 2012, http://aim.tkgristmill.com/.

[78] R Development Core Team, "A language and environment for statistical computing," R Foundation for Statistical Computing, Vienna, Austria, 2009, http://www.R-project.org.

[79] E. F. Pettersen, T. D. Goddard, C. C. Huang, G. S. Couch, E. C. Meng, and T. E. Ferrin, "UCSF Chimera: a visualization system for exploratory research and analysis," Journal of Computational Chemistry, vol. 25, pp. 1605-1612, 2004.

[80] F. Caruso, M. Rossi, A. Benson et al., "Ruthenium-arene complexes of curcumin: $\mathrm{x}$-ray and density functional theory structure, synthesis, and spectroscopic characterization, in vitro antitumor activity, and DNA docking studies of ( $p$ Cymene)ru(curcuminato)chloro," Journal of Medicinal Chemistry, vol. 55, pp. 1072-1081, 2012.

[81] C. S. K. Rajapakse, A. Martinez, B. Naoulou et al., "Synthesis, characterization, and in vitro antimalarial and antitumor activity of new ruthenium(II) complexes of chloroquine," Inorganic Chemistry, vol. 48, pp. 1122-1131, 2009.
[82] K. M. Omberg, J. R. Schoonover, J. A. Treadway, R. M. Leasure, R. B. Dyer, and T. J. Meyer, "Mid-infrared spectrum of $[\mathrm{Ru}(\mathrm{bpy}) 3]^{2+}$, , Journal of the American Chemical Society, vol. 119, no. 30, pp. 7013-7018, 1997.

[83] G. Bor, U. K. Dietler, P. L. Stanghellini et al., "Structural and infrared spectroscopic characterization of $\mathrm{Co}_{6} \mathrm{C}(\mathrm{CO})_{12} \mathrm{~S}_{2}$ : a high-nuclearity carbido carbonyl cluster spontaneously formed from dicobalt octacarbonyl and carbon disulphide," Journal of Organometallic Chemistry, vol. 213, no. 1, pp. 277-292, 1981.

[84] P. L. Stanghellini, L. Cognolato, G. Bor, and S. F. A. Kettle, "Identification of the IR frequencies of the interstitial carbon atom in some $\mathrm{M}_{6} \mathrm{C}(\mathrm{M}=\mathrm{Fe}, \mathrm{Ru})$ carbonyl clusters by ${ }^{13} \mathrm{C}$-enrichment," Journal of Crystallographic and Spectroscopic Research, vol. 13, no. 2, pp. 127-133, 1983.

[85] D. Cremer and J. Grafenstein, "Calculation and analysis of NMR spin-spin coupling constants," Physical Chemistry Chemical Physics, vol. 9, pp. 2791-2816, 2007.

[86] R. Gaur and L. Mishra, "Synthesis and characterization of $\mathrm{Ru}(\mathrm{II})-\mathrm{DMSO}-\mathrm{Cl}$-chalcone complexes: DNA binding, nuclease, and topoisomerase II inhibitory activity," Inorganic Chemistry, vol. 51, pp. 3059-3070, 2012.

[87] J. Pratuangdejkul, P. Jaudon, O. C. Ducrocq et al., "Cation- $\pi$ interactions in serotonin: conformational, electronic distribution, and energy decomposition analysis," Journal of Chemical Theory and Computation, vol. 2, pp. 746-760, 2006.

[88] T. Helgaker and M. Jaszunski, "Ab initio methods for the calculation of NMR shielding and indirect spin-spin coupling constants," Chemical Reviews, vol. 99, pp. 293-352, 1999.

[89] T. Yoshizawa and M. Hada, "Relativistic quantum-chemical calculations of magnetizabilities of noble gas atoms using the Douglas Kroll Hess method," Chemical Physics Letters, vol. 458, pp. 223-226, 2008.

[90] C. Foroutan-Nejad, "Interatomic magnetizability: a QTAIMbased approach toward deciphering magnetic aromaticity," The Journal of Physical Chemistry A, vol. 115, pp. 12555-12560, 2011.

[91] T. Mineva, E. Sicilia, and N. Russo, "Density-functional approach to hardness evaluation and its use in the study of the maximum hardness principle," Journal of the American Chemical Society, vol. 120, no. 35, pp. 9053-9058, 1998.

[92] G. de Luca, E. Sicilia, N. Russo, and T. Mineva, "On the hardness evaluation in solvent for neutral and charged systems," Journal of the American Chemical Society, vol. 124, no. 7, pp. 1494-1499, 2002.

[93] T. Mineva, V. Parvanov, I. Petrov, N. Neshev, and N. Russo, "Fukui indices from perturbed Kohn-Sham orbitals and regional softness from Mayer atomic valences," The Journal of Physical Chemistry A, vol. 105, no. 10, pp. 1959-1967, 2001.

[94] R. G. Pearson and J. Chem, "Recent advances in the concept of hard and soft acids and bases," Journal of Chemical Education, vol. 64, pp. 561-567, 1987.

[95] A. A. Adeniyi and P. A. Ajibade, "Theoretical study of the electronic and spectroscopic properties of some $\mathrm{Ru}(\mathrm{II})$ anticancer complexes," Spectrochimica Acta A: Molecular and Biomolecular Spectroscopy, vol. 105, pp. 456-465, 2013.

[96] P. J. Mendesa, J. P. P. Ramalho, A. J. E. Candeias, M. P. Robalod, and M. H. Garcia, "Density functional theory calculations on $\eta^{5}$-monocyclopentadienylnitrilecobalt complexes concerning their second-order nonlinear optical properties," Journal of Molecular Structure: THEOCHEM, vol. 729, pp. 109-113, 2005.

[97] I. C. de Silva, R. M. de Silva, and K. M. N. de Silva, "Investigations of nonlinear optical (NLO) properties of $\mathrm{Fe}, \mathrm{Ru}$ 
and Os organometallic complexes using high accuracy density functional theory (DFT) calculations," Journal of Molecular Structure: THEOCHEM, vol. 728, no. 1-3, pp. 141-145, 2005.

[98] E. E. Ebenso, D. A. Isabirye, and N. O. Eddy, "Adsorption and quantum chemical studies on the inhibition potentials of some thiosemicarbazides for the corrosion of mild steel in acidic medium," International Journal of Molecular Sciences, vol. 11, pp. 2473-2498, 2010. 

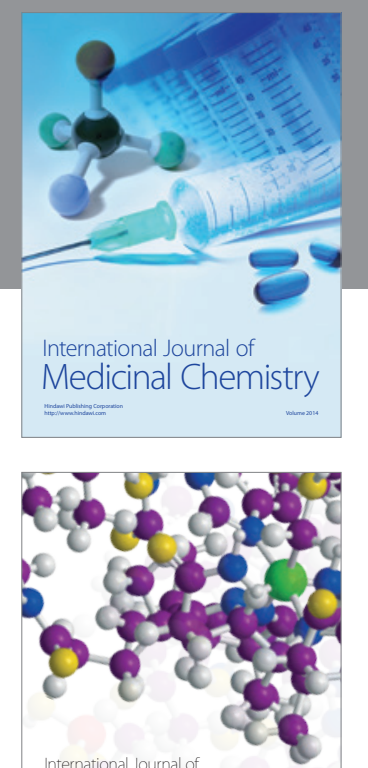

\section{Carbohydrate} Chemistry

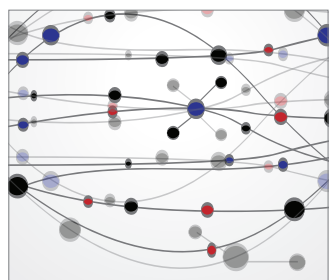

The Scientific World Journal
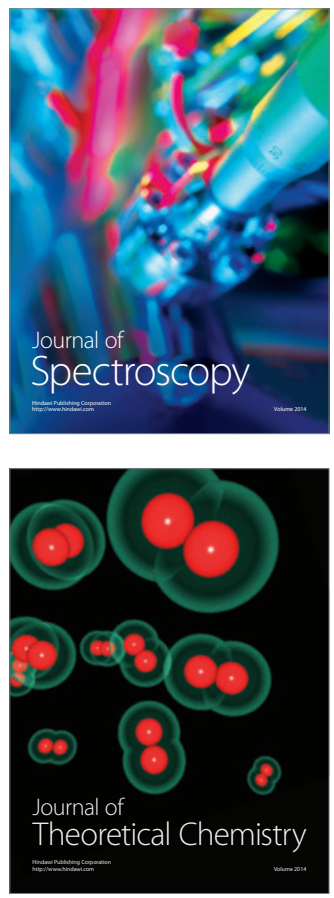
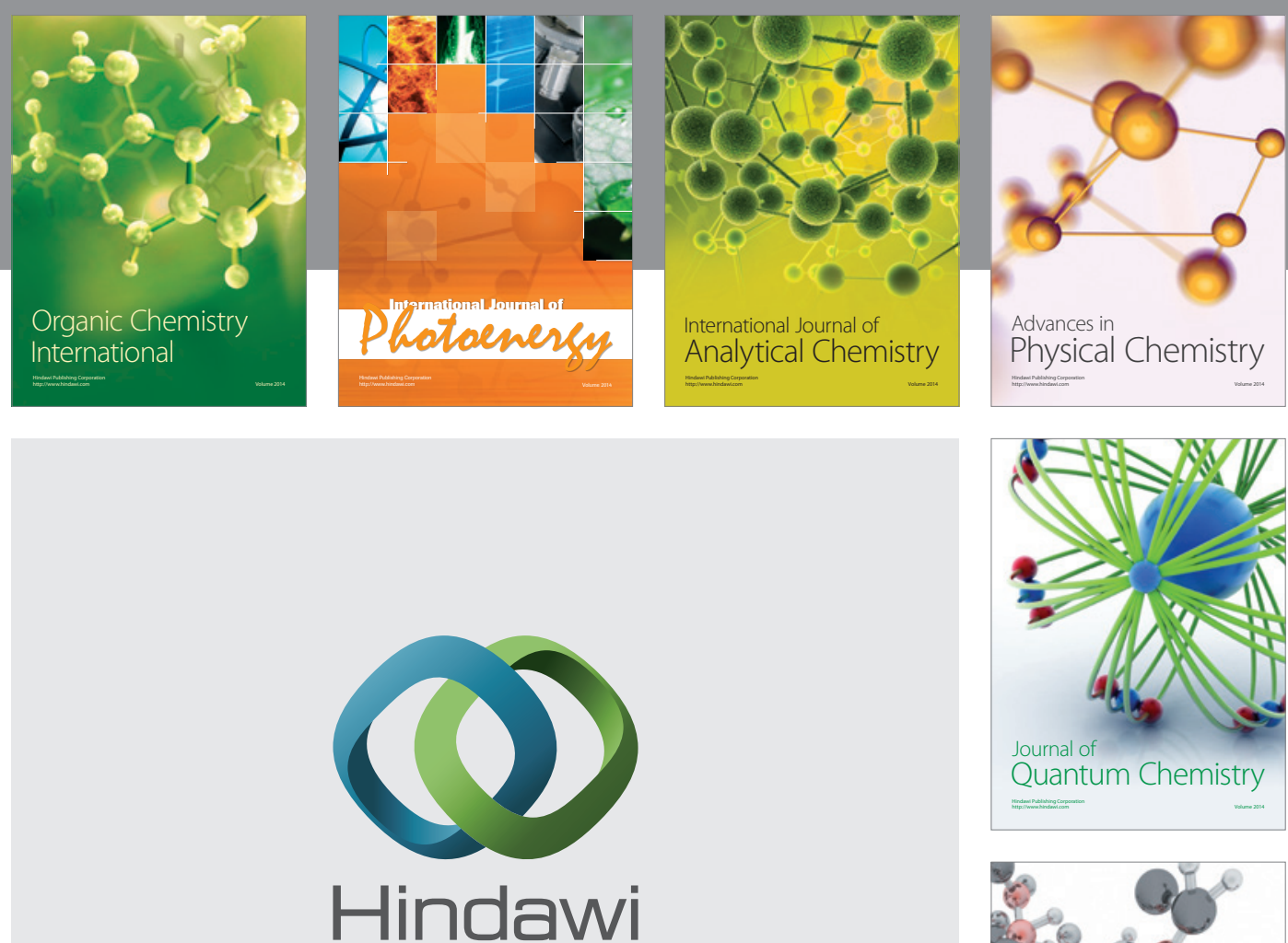

Submit your manuscripts at

http://www.hindawi.com

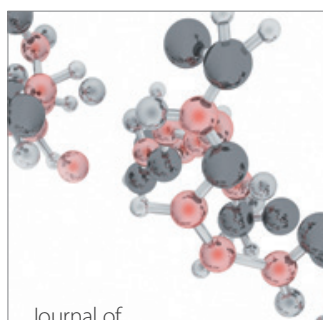

Analytical Methods

in Chemistry

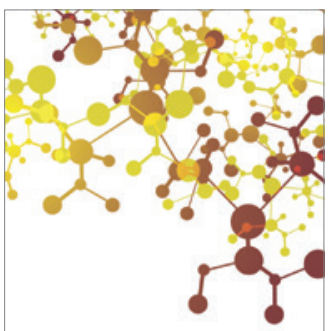

Journal of

Applied Chemistry

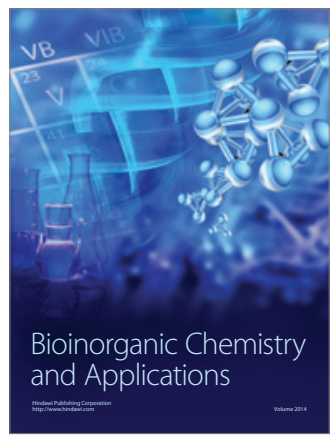

Inorganic Chemistry
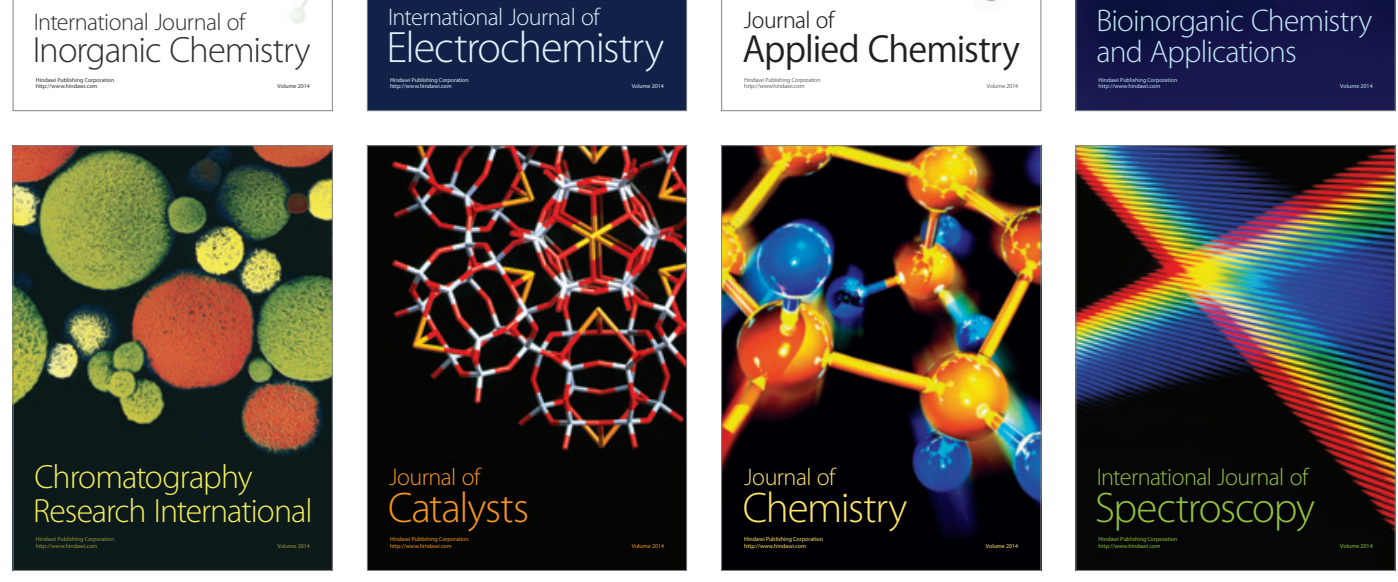